\title{
Update on the NASA Glenn Propulsion Systems Lab Icing and Ice Crystal Cloud Characterization (2017)
}

\author{
Judith F. Van Zante ${ }^{1}$, Thomas P. Ratvasky ${ }^{2}$ \\ NASA Glenn Research Center, Cleveland, OH, 44135 \\ Timothy J. Bencic ${ }^{3}$, Clark C. Challis ${ }^{4}$ \\ HX5 Sierra, Cleveland, OH, 44135 \\ Emily N. Timko ${ }^{5}$ \\ Jacobs Technology, Inc., Cleveland, OH, 44135 \\ Mark R. Woike ${ }^{6}$ \\ NASA Glenn Research Center, Cleveland, OH 44135
}

NASA Glenn's Propulsion Systems Lab, an altitude engine test facility, generates icing clouds with a spray system. While the spray system is used mostly to create ice crystal clouds (Appendix D/P), the 2017 cloud characterization effort added the requirement to produce exactly supercooled liquid clouds in Appendix $C$ and Appendix 0 . Success was demonstrated to supercool the largest drops at the warmest conditions, but not freeze out the smallest drops at the coldest conditions. This paper documents primarily the total water content characterization methodology and results from an Iso-Kinetic Probe in ice crystals and Multi-Wire sensor in supercooled liquid, along with the cloud uniformity provided by light extinction tomography. Particle size distribution results from High Speed Imaging probes and a Phase Doppler Interferometer are discussed. Also, a new numerical model for tracking the thermodynamics of the air-drop interactions in PSL from the plenum toward the cloud characterization plane are noted. Both of these latter topic are more fully documented in companion papers.

$\begin{array}{ll}\text { BH } & =\text { Background Humidity, ppm (dry) } \\ \text { CF } & =\text { Concentration Factor } \\ \text { DeltaP } & =\text { Pwat }- \text { Pair (psid) } \\ \text { DEP } & =\text { Duct Exit Plane } \\ \text { DI } & =\text { De-ionized } \\ \text { Escort } & =\text { PSL's steady state data acquisition and processing system } \\ \text { HSI } & =\text { High Speed Imaging probe, particle sizing probe } \\ \text { I } & =\text { Intensity of light from tomography measurement }\end{array}$

${ }^{1}$ Technical Lead: Icing Engineering, Testing Division, 21000 Brookpark Rd, MS 6-7, and AIAA Senior Member.

${ }^{2}$ Aerospace Engineer, Research and Technology Division, 21000 Brookpark Rd, MS 11-2, and AIAA Senior Member

${ }^{3}$ Optical Diagnostics Expert, HX5 Sierra, 21000 Brookpark Rd, MS 6-2.

${ }^{4}$ Data Engineer, HX5 Sierra, 21000 Brookpark Rd, MS 125-2.

${ }^{5}$ Cloud Calibration Specialist, Jacobs Technology, 21000 Brookpark Rd, MS 6-2.

${ }^{6}$ Research Engineer, Optics and Photonics Branch, 21000 Brookpark Rd, MS 77-6 


\begin{tabular}{|c|c|c|}
\hline IC & $=$ & Ice Crystal \\
\hline ICD & $=$ & Ice Crystal Detector, water content probe \\
\hline IKP & $=$ & Iso-Kinetic Probe, water content probe \\
\hline iWC & $=$ & Ice Water Content $\left(\mathrm{g} / \mathrm{m}^{3}\right)$ \\
\hline LWC & $=$ & Liquid Water Content $\left(\mathrm{g} / \mathrm{m}^{3}\right)$ \\
\hline Ма & $=$ & Mach number \\
\hline MVD & $=$ & Median Volumetric Diameter (micron) \\
\hline MW & $=$ & Multi-wire, water content probe \\
\hline N1 & $=$ & Fan speed (rpm) \\
\hline Pair & $=$ & Spray nozzle atomizing air pressure (psid) \\
\hline Particle & $=$ & Ice crystal or liquid drop issued by the spraybar system \\
\hline PDI & $=$ & Phase Doppler Interferometer, particle sizing probe \\
\hline Ps & $=$ & Pressure, static \\
\hline PSD & $=$ & Particle Size Distribution \\
\hline $\mathrm{Pt}$ & $=$ & Pressure, total, measured in the Plenum (psia) \\
\hline PTank & $=$ & Pressure in Tank, simulating altitude (psia) \\
\hline Pwat & $=$ & Spray nozzle water pressure (psid) \\
\hline RFP & $=$ & Rearward Facing Probe, measures temperature and specific humidity \\
\hline RHPL & $=$ & Relative humidity in the plenum (\%) \\
\hline RTD & $=$ & Resistance Temperature Detector, measures temperature \\
\hline SCL & $=$ & Supercooled Liquid \\
\hline Std & $=$ & Standard nozzle \\
\hline TADAS & $=$ & Thermodynamic Air - Drop Algorithm Simulation, 1D steady state model \\
\hline Tair & $=$ & Temperature of spray atomizing air, measured at bar inlet \\
\hline $\mathrm{Tt}$ & $=$ & Temperature, total, measured in the plenum (F) \\
\hline Ts & $=$ & Temperature, static \\
\hline Twat & $=$ & Temperature of spray water, measured at bar inlet \\
\hline Twb & $=$ & Temperature, wet bulb (F), subscript $t$ for total, s for static \\
\hline TWC & $=$ & Total Water Content $\left(\mathrm{g} / \mathrm{m}^{3}\right)$ \\
\hline Wa & $=$ & Air mass flow rate (lbm/s) \\
\hline Ww & $=$ & Water mass flow rate, from spraybars $(\mathrm{lbm} / \mathrm{s})$ \\
\hline um & $=$ & micron \\
\hline$(\mathrm{x}, \mathrm{r}, \theta)$ & $=$ & Cylindrical coordinates: $\mathrm{x}$-in $=$ axial, $\mathrm{r}$-in $=$ radial, $\theta$-deg= circumferential (primary) \\
\hline$(\mathrm{x}, \mathrm{y}, \mathrm{z})$ & $=$ & Cartesian coordinates: $\mathrm{x}$-in $=$ axial, $\mathrm{y}$-in \& $\mathrm{z}$-in $=$ cross-stream \\
\hline
\end{tabular}

(Pwat, Pair; DeltaP) is used to identify spray pressure conditions

Subscripts

$\begin{array}{lll}00 & = & \text { Measured value at duct center } \\ 1 & = & \text { Value at Station 1, the aero-thermal plane just upstream of test article } \\ \text { Bulk_M } & = & \text { Measured bulk value, calculated from TWC_00 and tomography CF } \\ \text { Ww } & = & \text { Calculated bulk (average) TWC from injected water flow and air mass flow rates. Assumes } \\ & \text { cloud is uniform over full duct. }\end{array}$




\section{Introduction}

WASA Glenn's Propulsion Systems Laboratory (PSL), an altitude engine research test facility, was outfitted in 2011 with a spray system for the purpose of introducing ice crystals into the face of a running turbine engine or driven rig, Ref. [1-5]. Since then, the facility's spray system has undergone several upgrades and improvements; these include improvements to the spray system by adding solenoids to each nozzle for faster response, and insulating the bars to reduce or eliminate issues with nozzles freezing.

Cloud characterizations occur prior to each engine or driven rig icing test, Ref. [6, 7]. These two types of tests have very different total conditions they are trying to match. The engine needs PSL to simulate atmospheric flight conditions, while the driven rig needs to simulate the environment behind the fan. Cloud extent, Total Water Content, TWC, and Median Volumetric Diameter, MVD, targets can also vary test to test. This report describes the fourth cloud calibration effort conducted in support of the Honeywell Uncertified Research Engine, HURE.

Goals for this particular engine test helped to expand the facility and measurement capabilities. One goal was to utilize NASA's 1D Icing Risk Analysis Code to identify inlet conditions that lead to potential ice accretions sites inside an engine. The code does this by tracking the static wet bulb temperature, Twbs, melt ratio, and Ice Water to Air Ratio (IWAR) through the engine. If the particles have started to melt within a certain Twbs range (492-498 R) and IWAR $(<0.002)$, there is a likelihood of accretion. The basis of this criteria is described in Ref. [8]. By finding regions of icing, parameter sweeps were conducted to move the location of accretion and change the accretion characteristics. By forcing the location of target accretion sites, sometimes the test condition landed outside of Appendix D. Another goal was to evaluate the engine in supercooled liquid conditions, SCL, with both smaller (Appendix C) and larger (Appendix O) drop sizes. The challenge of this calibration was to identify facility conditions that produce exactly SCL particles. In addition, the desire was to push the cloud toward the fan tips, accepting the potential risk of ice accretion on and shedding from the contraction walls.

\section{Facility Description}

PSL simulates flight conditions by pumping down the 39-ft long by 24-ft diameter test cell to the desired pressure altitude, PTank, then increasing the pressure in the plenum, Pt. This supply air is externally conditioned and initially very dry. As verified by aero-thermal calibrations, PSL is an adiabatic and isentropic facility. Therefore, the relationship between Pt and PTank defines the Mach number, Ma, and air mass flow rate, Wa. The total temperature, Tt is controlled by turbo expanders. The test cell and duct work can be seen in Fig. 1.

The plenum is 18-ft in diameter. Upstream of the cloud-generating spraybars is a flow-straightening grid, 6-in long, with a 2x2-in stainless steel mesh. These can be seen in Fig. 2a. A fiberglass liner has been added to create a smooth contraction to the bulkhead, which is about 88-in diameter. To control and stabilize relative humidity in the plenum, RHPL, steam can be injected well upstream so that it is fully mixed at the plenum. The water vapor content in the plenum is measured by a Spectra Sensor Atmospheric Water Vapor Sensing System (WVSS-II). These four parameters, Pt, PTank, Tt and RHPL, set the atmospheric flight condition (Ma1, Ps1, Ts1) presented to the test article.

The plenum holds 10 spraybars with alternating patterns of Mod1 and Standard (Std) nozzles, also seen in Fig. 2a. Note these are the same nozzles used at PSL's sister facility, the Icing Research Tunnel, IRT. Each of the 112 Mod1s or 110 Std nozzles can be individually turned off or on. Each air atomizing nozzle is internally mixed. The icing station operator sets the spraybar water flow rate to achieve the desired pressure, Pwat, and the desired atomizing air pressure, Pair, is referenced to the plenum pressure, Pt. The system is designed to cool the spraybar air and water, but generators can be rented to heat the spraybar air and water 
to a controlled temperature. While the icing station operator controls to Pwat and Pair, and their individual temperatures, Twat and Tair, cloud calibrations are based upon DeltaP = Pwat - Pair.

The spraybars have a rounded leading edge, but a bluff trailing edge. This is to accommodate the eight spraybar cooling air ports surrounding each nozzle exit. A close up of the nozzle and cooling air ports is shown in Fig. 2b. Cox \& Co. Inc., who designed the system, added these ports to help ensure the liquid water drops would freeze, Ref. [9]. The spraybar cooling air ports deliver air at a controllable pressure, P_SBCA and temperature, T_SBCA. This temperature can be liquid nitrogen cooled.

Typically filtered, but non-demineralized city water is used to create fully glaciated clouds. This 'city' water helps ensure nucleation sites for particle freeze-out. PSL can also de-ionize (DI) the water. When the target is supercooled liquid, the water is deionized to $3 \mathrm{MOhm}$ resistivity; this is achievable in under 90 minutes. To achieve the same cleanliness as the IRT, 6-8 MOhm, would take about eight hours.

After the bulkhead, shown in Fig. 1, the remaining ductwork is configurable; this affects the contraction ratio and distance from the spraybars. The base calibration and Fundamental Icing Test, Ref. [10], configuration utilizes a 36-in duct, or 27:1 contraction ratio from the plenum to the calibration plane. The contraction ends about 20-ft from the spraybars, and the constant-area 36-in duct begins; it runs 8-ft. The first spool piece is 3-ft long and is called 'Station 1'. This is where pressure and temperature rakes are located during an Aero-Thermal calibration. The 2017 Aero-Thermal Calibration is detailed in Ref. [11]. The next spool piece is a 1-ft long Tomography duct. Aft of that is the 3-ft Cloud Calibration Duct. The ductwork concludes at the Duct Exit Plane, DEP.

Facility simulation of atmospheric flight parameters and ranges are:

- $\quad$ Duct size (12 to 88-in) and distance from spraybars

- $\quad$ Pressure altitude, PTank, from 12.7 to 2.1 psia, corresponding altitudes from 4 to $45 \mathrm{kft}$

- Mach, Ma, up to 0.8, or Air Mass Flow Rate, Wa, from 50 to $330 \mathrm{lbm} / \mathrm{s}$ (set by Pt)

- Inlet total temperature, $T t$, from -50 to $+50 \mathrm{~F}$

- $\quad$ Plenum relative humidity, $R H P L$, from ambient (0.3 to $3 \%$ ) to $50 \%$.

Cloud generation parameters and ranges are:

- Nozzle set, Standards or Mod1s

- Water Pressure, Pwat, from 10 to 350 psid

- Air Pressure, Pair, from 5 to 90 psid

- Water Temperature, Twat, from 45 to $180 \mathrm{~F}$

- Air Temperature, Tair, from 45 to $180 \mathrm{~F}$

- Water source, from 'city' to de-ionized

- Spraybar Cooling Air Pressure, P_SBCA, optional, from 5 to 30 psid

- Spraybar Cooling Air Temperature, T_SBCA, optional, from -20 to +40 F

\section{Setting Conditions in PSL}

The flight condition in the facility is set by the static temperature, static pressure, Mach number and effective area at a plane - usually at or near the interface between the facility and the test article. The air mass flow rate required for those conditions is then calculated. Conservation of mass is used to calculate the static and total conditions in the cloud calibration duct and in the plenum. Fortunately, aero-thermal calibrations confirm that PSL conforms to adiabatic and isentropic assumptions, Ref. [11]. Setting Pt and Tt sets the total conditions sent to the test article. During the calibration, when the test article was not present, Pt and Tt were set to the target conditions while PTank was adjusted to maintain the target flow rate. PTank changed with the different probe installations. 


\section{Cloud Generation Considerations}

Physics in the Plenum

How the cloud forms in the plenum drives how it presents at the DEP. The spray issues as liquid water particles into an unsaturated plenum. The amount of evaporation from the spray is strongly influenced by RHPL, Tt and Pt, but other parameters contribute as well. Higher Pair cause locally more significant temperature drops at the shock wave, if present (if $\mathrm{Pt} /(\mathrm{Pt}+$ Pair $) \leq 0.528)$ ). Spraybar Twat and Tair can also impact the amount of evaporation. Spraybar cooling air temperature, T_SBCA and pressure, P_SBCA, have been shown to have a significant effect on not only breaking up the nozzle plume, but adding really dry air (dew point temperature $<-50 \mathrm{~F}$ ) at the nozzle exit. As the particles travel further into the contraction, they accelerate and cool even more due to the static temperature drop and accompanying static wet-bulb temperature drop, Twb_s. Some might even freeze. Despite the increase in relative humidity, the static wetbulb temperature decreases due to the static temperature drop in the contraction. If saturation is reached, Twb_s equals static temperature. At saturation, it is speculated that some of the water vapor re-deposits onto the existing particles; preferentially on ice crystals over water drops due to their difference in saturation vapor pressure.

A Thermodynamic Air - Drop Algorithm Simulation code (TADAS) was developed to capture these complex interactions and try to predict the cloud at the DEP, Ref. [12-14]. This steady state 1-D model utilizes the PSL axial geometry, the environment in the plenum, and an estimate of the initial particle size distribution, PSD, based upon those measured at the IRT. It then tracks the thermodynamic interaction between the particles and air through the contraction and constant-area duct. In general, it showed that the particles spend $80 \%$ of their time developing in the plenum before accelerating through the contraction toward the DEP. It also showed minimal change in the constant-area duct, and downstream in the jet core flow. This is reassuring, as that is where the particle sizing probes were located. This tool also proved to be extremely helpful forecasting conditions in these new-to-PSL regimes.

For many of the SCL cases to be tested, the TADAS code predicted, and the instruments measured, significant evaporation; sometimes more than $75 \%$ of the injected water turned to vapor at the DEP. Select cases from the TADAS code are presented in Table 1. Shown are the initial conditions in the plenum and the final predicted conditions at the DEP for TWC, MVD (= Dv50) and Melt Ratio. The Melt Ratio is the liquid to total water content ratio; if zero, the cloud is fully glaciated, if one, fully liquid. Predictably, higher evaporation rates not only reduce the TWC, but typically drive an increase in MVD as well. Note that for the SCL Test Point \# 2.02, $0.35 \mathrm{~g} / \mathrm{m} 3$ or nearly $80 \%$ of the cloud has evaporated and the MVD increased by nearly $50 \%$. This code proved useful when trying to understand what the injected TWC and MVD should be to hit the targets at the DEP. This code also predicted that IC Test Point \# 19.10 would never freeze-out, allowing the researchers time to change the atmospheric flight condition.

To further illustrate how complicated the calibration process was, Fig. 3 shows the change in MVD and TWC over two fan speed, N1, sweeps. The target SCL cloud, set as the initial condition in the plenum, was run through the TADAS code for the various N1 changes. The amount of evaporation was a function of $\mathrm{N} 1$. Thus, to hit the target conditions at the DEP, the researcher needed to figure out a rough algorithm to accommodate the varying effects.

Since earlier investigations, Ref. [6, 10], identified radial changes in the cloud characteristics, traversing systems are being added to PSL's capabilities. These systems, however, were not completed in time for Phase 1 of this 2017 calibration effort. 
Table 1. TADAS Model. Sample SCL and IC results showing effect of evaporation.

\begin{tabular}{|c|c|c|c|c|c|c|c|}
\hline \multirow[b]{2}{*}{ Test Point \# } & & \multicolumn{2}{|c|}{ Supercooled Liquid } & \multicolumn{2}{|c|}{ Ice Crystal } & \multirow[b]{2}{*}{19.07} & \multirow[b]{2}{*}{19.10} \\
\hline & & 2.02 & 2.03 & 19.01 & 19.02 & & \\
\hline \multicolumn{8}{|l|}{ TWC } \\
\hline Initial, i & {$\left[\mathrm{g} / \mathrm{m}^{3}\right]$} & 0.45 & 1.08 & 3.44 & 3.42 & 3.39 & 3.36 \\
\hline Final, $f$ & {$\left[\mathrm{~g} / \mathrm{m}^{3}\right]$} & 0.09 & 0.74 & 2.84 & 2.72 & 2.31 & 2.00 \\
\hline Dif. $(f-i)$ & {$\left[\mathrm{g} / \mathrm{m}^{3}\right]$} & -0.36 & -0.34 & -0.60 & -0.70 & -1.07 & -1.35 \\
\hline Ratio $(f-i) / i$ & {$[\%]$} & -80 & -31 & -17 & -20 & -32 & -40 \\
\hline \multicolumn{8}{|l|}{ Dv50 } \\
\hline Initial, i & [um] & 20.1 & 35.6 & 39.9 & 39.9 & 39.9 & 39.9 \\
\hline Final, $f$ & [um] & 37.1 & 48.4 & 37.8 & 38.9 & 47.1 & 56.9 \\
\hline Dif. $(f-i)$ & [um] & 17.0 & 12.8 & -2.1 & -1.0 & 7.1 & 16.9 \\
\hline \multicolumn{8}{|c|}{ Total Melt Ratio } \\
\hline Initial & [ ] & 1.00 & 1.00 & 1.00 & 1.00 & 1.00 & 1.00 \\
\hline Final & [ ] & 1.00 & 1.00 & 0.00 & 0.01 & 0.14 & 1.00 \\
\hline
\end{tabular}

With the high number of influential parameters, the increased scope to add SCL conditions, and the extremely limited time frame, an effort was made to reduce the parameter space as much as feasible. Therefore, the following was determined: Eliminate the use of the spraybar cooling air system all together. For IC, continue to operate with city water at Twat $=$ Tair $=45 \pm 5 \mathrm{~F}$, and RHPL $=45 \pm 5 \%$. It was not clear, however, how to set up the facility for SCL conditions. For background, the IRT deionizes its water to 6-8 MOhm, heats Twat $=$ Tair $=180 \mathrm{~F}$, and operates in a near or fully saturated environment. For SCL in PSL, the water resistivity was to the highest, easily achievable setting. Next was to determine Twat, Tair and RHPL to hit exactly SCL conditions for MVD from 15 to $100 \mathrm{um}$, where the smallest drop is around 2 um and the largest around $500 \mathrm{um}$. The diagnostics for particle freeze-out came from the Phase Doppler Interferometer, PDI, and Multi-Wire, MW. The diagnostic for above-freezing large drops was visual evidence on unheated strut surfaces. Fortunately, over the atmospheric flight conditions tested, one set of values achieved this. SCL conditions were produced with DI water at $3 \pm 0.5 \mathrm{MOhm}$, Twat $=$ Tair $=180 \pm$ $5 \mathrm{~F}$, and RHPL $=45 \pm 5 \%$. It was important to set RHPL early in the calibration process, as it has significant effect on the cloud at the DEP.

\section{Schedule and Objectives}

A total of 13 days were allotted for this calibration effort, including one day for Aero-Thermal calibration. Due to the complexity of the test - the addition of two new appendices - as much data acquisition as could reasonably fit was packed into this effort. Time rates of change dominated the decision-making process. That is, the longest time events - changing instrument setup and water source - had to be done off runshift. With that limitation, the schedule shown in Table 2 was developed (individual instruments are described in Section V. Cloud Characterization Systems and Analysis). Note this did not leave a significant amount of time to explore a wide range of flight or cloud conditions. The longest time-sink conditions: coldest temperatures and highest air mass flow rates, were not explored during this test entry. To help manage the limited time for cloud generation, the researcher limited the atomizing air pressure ranges to those expected to allow the range of target MVDs, and gained higher fidelity curves.

Table 2 lists the test day, date, water source (DI for SCL, city for IC), primary instrument at duct center, objective of the test, then actual number of spray conditions acquired. Other cloud characterization instruments were installed off center on a non-interference basis. The TAT probe was fixed at $(+1,9,270)$, the RFP could traverse, but was typically located at $(+2,8.75,0)$. Either a MW or ICD was mounted at $(+2$, 8 or 10, 225); those results will not be reported here. The modular HSI and PDI were at $(+18$, about 6,270$)$. Of course, tomography data was captured as often as possible. On Test Day 1, 07/06/17, no data was acquired due to a facility issue and Test Day 4 was for the Aero-Thermal Calibration. Thus, the cloud 
characterization occurred with the remaining nine days. The final two days are scheduled for Jun 2019. These will include capturing radial profiles of select cases.

Table 2. Cloud Characterization Test Schedule.

\begin{tabular}{|cc|c|cl|c|}
\hline $\begin{array}{c}\text { Test } \\
\text { Day }\end{array}$ & Date & Phase & $\begin{array}{c}\text { Primary } \\
\text { Instrument }\end{array}$ & $\begin{array}{c}\text { O Test } \\
\text { Points }\end{array}$ \\
\hline 2 & $08 / 29 / 17$ & SCL & MW & Nozzle Optimization and Hunt for SCL & 19 \\
3 & $08 / 30 / 17$ & SCL & Raman & Nozzle Optimization and Hunt for SCL & 19 \\
5 & $09 / 07 / 17$ & SCL & IKP & LWC at $(0,0)$ & 21 \\
6 & $09 / 08 / 17$ & IC & IKP & iWC at $(0,0)$ & 23 \\
7 & $09 / 13 / 17$ & IC & HSI-FP & MVD at $(0,0)$ & 38 \\
8 & $09 / 14 / 17$ & SCL & HSI-FP & MVD at $(0,0)$ & 26 \\
9 & $09 / 18 / 17$ & IC & IKP & iWC at $(0,0)$ & 21 \\
10 & $09 / 19 / 17$ & SCL & IKP & LWC at $(0,0)$ & 27 \\
11 & $09 / 20 / 17$ & SCL & MW & LWC at $(0,0)$ & 29 \\
\hline
\end{tabular}

The first objectives were to optimize and finalize nozzle patterns, and to identify conditions required to produce exactly supercooled liquid conditions. That is, to not freeze-out the smallest particles at the coldest conditions, but also supercool the largest drops at the warmest conditions. It was expected that freeze-out is promoted with the atmospheric conditions of colder temperatures and lower pressures, but the effect of airspeed was uncertain. As it turns out, slower airspeeds favor a longer residence time, which dominate the effect of the smaller drop in static or wet bulb temperature, Ref. [12, 13]. At the same time, both Mod1 and Std nozzle patterns that produced as uniform a cloud as possible to the duct walls were identified. Finally, the MW allowed researchers to get a first glimpse of the predicted evaporation effects.

\section{Cloud Characterization Systems and Analysis}

Many of the systems used to characterize the cloud had been used previously, Ref. $[6,7,15]$. These systems and data analysis are briefly described in this section. A new coordinate system has also been introduced with this calibration and described next. Cloud characterizations results are found in Section VI.

\section{A. Coordinate System}

In preparation for using traversing systems in the future, a coordinate system was formally introduced with this effort. As can be seen from Fig. 4, both cylindrical (x, r, $\theta$ ) and Cartesian (x, y, z) coordinates are defined. The origin is at the DEP and center of the duct. The axial coordinate, $\mathrm{x}$, increases with the direction of flow. From the Aft Looking Forward, ALF, vantage, the duct wall is at $r=18$-in, and $\theta=0$-deg is at the 3 o'clock position, 90-deg is at the 12 o'clock and 270-deg is at the 6 o'clock. Similarly, positive y also points at 0 -deg at the 3 o'clock, with positive z pointing at the 12 o'clock position. All lengths are reported in inches, and the circumference is reported in degrees. Cylindrical coordinates are presented in this paper, unless otherwise noted.

\section{B. Uniformity}

The tomography system captured the cloud uniformity data in the plane at $\mathrm{x}=-42$-in, or 42 -in into the constant area duct. It physically can be seen in Fig. 1; a more complete description can be found in Ref. [15]. Light extinction tomography uses a series of laser sources and fiber optic coupled detectors around the duct. Each source is sequentially pulsed and measured by the detectors to determine the light extinction. The procedure is to acquire a cloud-off measurement just prior to each spray as a reference. The system then operates again with the cloud on. The attenuated intensities due to cloud particles in the flow are recorded by each detector. The natural log of the ratio of the cloud on to cloud off intensity, I, is calculated 
and the tomographic reconstruction is computed generating a 2-D map of the cloud. The system is typically run for $30-60$ sec to obtain a time-averaged cloud. It can be run on demand and return initial particle number density and uniformity results within 3 to 4 seconds. Fully processed results can be available within $2-3$ minutes. The output is the intensity ratio, I_ij, at pixel (i, j) over the cross-sectional tomography plane. Sample results are shown in Fig. 5. With the successful effort to push the cloud toward the outer walls as much as possible, the valid tomography radius changed from $r=12$ to 15 -in.

The center 1x1-in area of the duct was averaged to determine the I_00 value. A Concentration Factor, CF, over the duct cross-section can then be calculated

$$
\text { CF }=\text { I_00 / } \Sigma \Sigma \text { I_ij }
$$

Applying the tomographic CF to the measured TWC data at duct center yielded the bulk TWC in the duct.

$$
\text { TWC_Bulk_M = TWC_00 / CF }
$$

The quick access to this information proved invaluable, allowing real-time adjustments in spray pressures to compensate for the high evaporation experienced during this calibration.

\section{Total Water Content}

As described previously, Ref. [6, 7] for a set of flight and spray conditions, measurements of TWC are made at the center of the 36-in diameter calibration plane upstream of the DEP using either an Iso-Kinetic Probe version 2, IKP2 or Multi-wire, MW. Data were acquired with the WCM-2000 and processed by the M300 data acquisition system. All are made by SEA, Inc. These instruments were installed sequentially for center-point measurements. The procedure was to start from a stable, cloud-off baseline, turn the cloud on for 2 to 3-min, then turn the cloud off. Pre- and post-spray data were recorded to account for dry-terms. The stable, cloud-on data (ignoring the cloud on/off transients) were averaged to obtain a TWC for each condition. Several points were repeated throughout a run shift to check for city water contamination or drift.

The IKP2, shown in Fig. 6, was installed with the inlet tip inside the duct at centerline at $(-19,0,0)$. The IKP2, made by SEA, Inc. and NRC Canada, works on the principle of ingesting air and cloud particles into the probe isokinetically (no loss or gain of cloud particle mass), evaporating all hydrometeors regardless of phase, then measuring the total water vapor (background humidity + evaporated liquid water drops and/or ice particles). The total water content of the hydrometeors is determined by subtracting the background humidity, $\mathrm{BH}$, from the measured water vapor in the IKP2 flowpath. Water vapor measurements in the IKP2 and the ambient air are made with two LiCOR 840A water vapor instruments. Background humidity measurements are further explored in the next subsection. The IKP has been more thoroughly described in other publications, Ref. [16, 17].

The IKP2 was designed to measure TWC in high concentrations of ice crystals at higher altitude flight conditions, and has been shown to work well in that environment. At warmer temperatures, the amount of water vapor contained in saturated air increases significantly. So at Ts $=-10 \mathrm{C}$, the amount of water vapor contained in saturated air is $2.4 \mathrm{~g} / \mathrm{m}^{3}$, and at Ts $=0 \mathrm{C}$, it is approximately $4.9 \mathrm{~g} / \mathrm{m}^{3}$. With such large $\mathrm{BH}$ levels at these warmer temperatures, the accuracy of TWC measured by the IKP2 is reduced, particularly at low TWC values. For example, with a cloud at Ts $=-10 \mathrm{C}$ and TWC $=0.1 \mathrm{~g} / \mathrm{m}^{3}$, the TWC uncertainty is $50 \%$. But with a cloud at Ts $=-10 \mathrm{C}$ and TWC $>1 \mathrm{~g} / \mathrm{m}^{3}$ a, the uncertainty was less than $4 \%$, Ref. [16].

To accurately measure the TWC in SCL conditions, or Liquid Water Content, LWC, a Multi-Wire, MW, was positioned at $(-20,0,0)$, shown in Fig. 7. Further detail on the MW can be found in Ref. [18, 19]. TWC from a MW has been shown to closely match that of an IKP in SCL clouds in Icing Wind Tunnels, Ref. [17], but is much lower, about 60\%, in IC clouds. Furthermore, MWs are decent phase discriminators. The 
half-pipe element catches ice crystals that bounce off the cylindrical elements, so ratios of these elements can indicate phase to some degree. Ratios closer to zero indicate glaciation, while ratios closer to one indicate liquid. As in previous calibrations, a splitter plate placed between the mounting strut and the sensor head helped align the flow into the shroud and isolated the sensing elements from the effect of any accretion on the strut, see Fig. 7a. A collection efficiency is applied to the MW per Ref. [20].

For this characterization effort, a secondary location TWC location was added at (+2, 8 or 10, 225). The purpose was to help investigate the radial profile measured by the tomography system. Either the MW or an Ice Crystal Detector, ICD, were placed here. The ICD, shown in Fig. 7b, can be thought of as a hybrid of the MW and robust probe: a concave 2-mm dia. half-pipe is located at the top leading edge of a symmetric airfoil body. A convex 2-mm dia. half pipe is located immediately below it, also at the leading edge. The leading edge location improves the collection efficiency compared to the shrouded MW design, and makes the design more robust, or less susceptible to damage. The ICD was included on a trial bases; the results will not be included in this report. The ICD is also made by SEA, Inc., Ref. [21].

\section{Background Humidity}

During the IKP2 test days, three sources of background humidity were available. LiBack1 used a LiCOR840A to measure air sampled through a bent 0.25 -in OD tube with the inlet facing downstream. The tube was mounted at the top of the duct (12 o'clock position) and the inlet was positioned at $(-14,6,90)$. It can be seen in Fig. 6. A deflector cone was sometimes used on the tube to reduce water/ice ingestion in the air line. LiBack2 also used a LiCOR840A to measure air sampled through an aft facing port near the front dome of the IKP2 canister. This was a new development to acquire background water vapor on the IKP2 canister. This location was $(0,3,225)$. A third source of background humidity came from the Rearward Facing Probe, RFP. The RFP was able to traverse from outside the duct toward center along $\theta=0$. Typically, it was located at $(+2,8.75,0)$. The inlet to the RFP incorporated a cap to limit particle and runback water ingestion. The probe is visible in Figs. 7a and 8. The RFP was piped to a Spectra Sensor Model WVSS-II. Air flow through each of the humidity sensors was enabled by a vacuum system. Flow rates were monitored and optimized to reduce time lags and reduce contamination in the line by pulling in water particles from the free stream. Careful analysis was conducted to look for such contamination, and managed through posttest processing. More on the RFP analysis can be found in Ref. [22].

\section{E. Particle Sizes}

Particle size distributions, PSD, were measured courtesy of two High Speed Imaging (HSI) probes and a Phase Doppler Interferometer, PDI. These are made by Artium Technologies, Inc. In this effort, the test was concluded before the Cloud Droplet Probe or Cloud Imaging Probe could be installed. The Dual Range Flight Probe, HSI-FPDR, was installed so that its measurement location was at $(+15,0,0)$. The modular, non-intrusive HSI and PDI systems were mounted with their measurement planes just upstream, at $(+12,0$, 0 ), shown in Fig. 8. When another probe was installed at duct center, the modular HSI and PDI systems were shifted to measure the PSD off-center, typically $(+12,4,270)$ or where sensible.

The HSI focuses several laser beams to a common spatial point. A CMOS camera, $640 \mathrm{x} 480$-pix, is focused at the illuminated point and acquires images at $300 \mathrm{~Hz}$. The digital resolution of both HSI instruments was $3.7 \mu \mathrm{m} /$ pixel. Particles in focus appear with crisp edges, where out of focus particles have diffuse edges. Assuming 3 contiguous pixels are required to identify a particle, the minimum particle size resolution is 7 um. Greater detail of the HSI and PDI systems, as well as the PSD results from this test are being presented in a companion paper, Ref. [23].

\section{F. Air and Particle Temperatures}

To measure air temperature, both a UTC Aerospace Systems TAT 102LJ2AG and an RTD in the RFP were used. While cloud-off air temperatures are more easily measured, the goal was to obtain accurate 
measurements of the cloud-on air temperature. Predictable changes were seen from cloud off to cloud on air temperatures. These results are reported in a companion paper, Ref. [22].

As part of NASA's instrumentation development effort, some calibration time was given to attempt the measurement of particle phase and temperature. Two different non-contact methods to determine whether the bulk average cloud contains liquid, ice or mixed-phase particles as well as determining the average temperature using Raman and fluorescence spectroscopy have been investigated since 2005. The sparse cloud and high speed flow, along with fiber-coupled laser excitation and detection lead to extremely low light levels. The optical setup utilized a 532-nm, 5-watt Continuous Wave laser fiber coupled into the test cell, Raman shifted light is fiber coupled to the detection system. These initial tests have been limited to using a spectrometer to detect the signal because the very low signal does not always distinguish itself against the high background light levels observed as the characteristic Raman water signature. Higher sensitivity detectors and bulk filtering of short and long areas will be used when confidence is obtained that the water spectrum is correct. For this entry, a newly designed head for the Raman scattering technique was employed. The head attempted to overcome the aforementioned issues with earlier designs, and is shown in Fig. 9. Unfortunately, this attempt was unsuccessful due to alignment issues and water contamination of the optics; no results will be reported here.

\section{Cloud Characterization \& Results}

The cloud was characterize near the DEP, as described in Section V. Results reported here include the light extinction tomography and water content probes. A comparison between the commercial off the shelf total air temperature sensor and the in-house rearward facing probe cloud-on air temperature and specific humidity are reported in Ref. [22]. For particle sizing, only the curve fits to the initially-processed data are described. A more complete description and final data analysis are reported in Ref. [23].

\section{A. Cloud Uniformity}

Recall the two objectives for cloud uniformity were:

1. Push the cloud as far as possible toward the outer wall at the DEP.

2. Optimize and fix the Mod1 and Standard nozzle patterns.

To achieve the first objective, the full radius of possible nozzles was turned on, up to $\mathrm{r}=78$-in in the plenum. Note this is different than previously reported calibrations, where the potential nozzle field was limited to $r=55$-in. The change in radius of nozzle candidates is highlighted yellow in Fig. 10. Also shown are the locations of the Mod1 (magenta) and Standard (green) nozzles.

Over the range of flight conditions of interest, three Mod1 patterns using 84, 36 and 26 nozzles, seen in Fig. 5a-c, and two Standard patterns using 77 and 43 nozzle were characterized, Fig. 5d-e. Select center nozzles were turned off to make the cloud mostly uniform, to within $\pm 20 \%$ of the center value, across as much of the duct as possible. Note that at higher altitudes or lower pressures in the plenum, the spray spread more and hit the walls. For these cases, some of the outermost nozzles had to be turned off.

\section{B. Total Water Content}

As illustrated for one engine, Ref. [4], total water content, TWC, is the more significant factor driving power loss events. Therefore, it is important to know the TWC presented to the face of the engine or driven rig. This section first discusses the bulk TWC calculation based upon the injected water, then the measured TWC at the center point of the DEP, combined with tomography to create the bulk measured TWC.

\section{Water Flow Calculations}

A factor based upon facility measurands or parameters calculated assuming isentropic and adiabatic flow, and independent of cloud characterization measurements, is most helpful in developing initial target spray 
pressures as well as a basis function. As described previously, Ref. [6, 7], the water injection or flow rate compared to the air flow rate can serve as this basis. The water flow rate, $\mathrm{Ww}$, is based upon the number on nozzles spraying, the type-specific average flow coefficient, Cfn (Cf_Mod1 $=0.005$, Cf_Std $=0.012$ ), and DeltaP:

$$
\mathrm{Ww}=\# \mathrm{Noz} * \mathrm{Cfn} * \sqrt{ }(\text { DeltaP })
$$

From here, a TWC basis function can be calculated. It assumes that all the water injected arrives at the DEP and is uniformly dispersed across the duct exit. Note it does not have a humidity parameter; but has been shown to work well when the calibration duct is saturated, which typically is valid.

$$
\text { TWC_Ww }=\mathrm{C} * \mathrm{Ww} * \mathrm{Ps} 1 /(\mathrm{Wa} * \mathrm{Ts} 1)
$$

where Ps1 and Ts1 are the static pressure and static temperature at Sta 1, and C is a constant that includes the density of water at $0^{\circ} \mathrm{C}$. If helpful, one can further assume a there is no cloud in a boundary layer or displacement thickness, $\delta$, in duct radius $\mathrm{R}$. The equation transitions to

$$
\text { TWC_Ww_D } \left.=\mathrm{C} * \mathrm{Ww} * \mathrm{Ps} 1 /(\mathrm{Wa} *((\mathrm{R}-\delta) / \mathrm{R}))^{2} * \mathrm{Ts} 1\right)
$$

With the nozzle-on radius in the plenum now set to 78-in, this $\delta$ is presumed to be 3-in. Previously, with the nozzle-on radius at 55 -in, $\delta$ had been set to 6 -in.

\section{IKP Results in Ice Crystals}

A typical time-history from the IKP2 results with ice particles is shown in Fig. 11. Spray ON is shown with the dashed line shifting from 0 to 1 . The pre-spray background water vapor measurements made with the IKP2 and the two Licor840 background humidity systems were reset to match the PSL_MMR_DEP made with the RFP. The top Panel A shows the water vapor measurements from the IKP2, two Licor840 background humidity systems, and the RFP. At Spray ON, there is an increase in the background humidity due to evaporation of the spray water. In Panel A, one can see there is a difference in the amount of background humidity increase sensed by the three different systems and there is a small lag in the $\mathrm{BH}$ response of the PSL_MMR_DEP sensed by the RFP. Panel B shows the water vapor data corrected for lags (ranged from 0-5 sec) in the BH systems. Panel C shows the 1-second IKP TWC data using the background humidity values from each of the three systems. The bottom Panel D shows the 5-sec moving average IKPTWC data using the background humidity values from each of the three systems. Note the differences in $\mathrm{BH}$ sensed by the three $\mathrm{BH}$ systems may be due to localized variation in background humidity. Although not shown in these figures, occasionally there were test points where water contaminated the Licor840 BHS inlets and $\mathrm{N}_{2}$ was used to purge the air lines. This occurred more often during the SCL tests. These factors and issues were considered for each test point and a selection was made on which background humidity was the best source for the IKP TWC calibration. The IKP TWC differences due to the source of BH were typically less than $10 \%$ of the TWC measurement.

The iWC_00 measured values from the IKP for both the Mod1 and Std nozzles in IC conditions are shown in Fig. 12a. The X-axis is TWC_Ww, the basis function described above, calculated from actual (vs target) conditions. These points show the full atmospheric and flight condition range tested. Off the chart is a Std datum at $5 \mathrm{kft}$; it would present at $(4.49,11.29)$.

Bulk values, iWC_Bulk_M, are plotted in Fig. 12b. Generally, the data are well-ordered, and the Std 5kft datum is now visible on the graph. Also presented on the graph are the linear trendline fits. These were used in the curve fits. Note these fits have a non-zero intercept. This represents a change from previous calibrations, where the best curve fit was also forced through zero. With the limited data set this trial, and 
the outside-of-Appendix D test points, this non-zero intercept was allowed. Also apparent on this plot is that some of the Mod1 data does not conform to the main curve. This effect was found to be isolated to warm (Ts1 > 12 F), lower altitude (Ps1 > 5.5 psia) points; it was dubbed 'Area 51'. If these conditions were met, the Area 51 curve fit was applied. With that, the goodness of fit plot for all IC conditions is shown in Fig 13. The TWC_Bulk_M values is the $\mathrm{x}$-axis and the resultant curve fit is the y-axis. One can see the data generally falls within the $\pm 20 \%$ band. Fig. $13 \mathrm{~b}$ shows detail of the Area 51 using the same legend. With that curve fit adjustment, the fit data are within the band.

\section{MW Results in Supercooled Liquid}

The requested SCL water contents were at lower Appendix C and Appendix O type conditions. Therefore, only the Mod1 nozzles were calibrated in SCL conditions. LWC data was taken with both the IKP and Multi-wire. For the MW, data from the TWC or half-pipe element were used in this analysis. Fig. 14a plots all the data from both sensors for all flight and cloud conditions. Seen in Fig. 14b are the bulk LWC values where the tomography CF was applied to the measured values. While all data is shown in Fig. 14a, only the 'clean' data are shown in Fig. 14b. Clean means contaminated tomography CFs are not included. There was an issue with a laser at the 12 o'clock position discovered post test; sometimes the laser beam was obstructed or amplified, causing erroneous readings. An example of contaminated tomography is shown in Fig. 5b. Even with this, the IKP data was less well-ordered than the MW data. Some effort was made to understand the origin of the scatter, but not successfully. Ultimately, only the MW data were chosen to develop the LWC curve fit.

To develop the LWC curve fit, the best-fit relationship between the LWC_Bulk_M and the basis TWC_Ww was sought. Both the typical linear fit and a polynomial fit of the clean data only were considered. The polynomial fit yielded better results and therefore was chosen, the equation is shown in Fig 15 . While only the clean LWC_Bulk_M data were used to develop the curve fit, all the data is plotted. With this equation, called Curve Fit \#1 in Fig. 16a, the goodness of fit was checked over the entire data set. Several data points were found to lie well outside the $\pm 20 \%$ line. To investigate, the ratio of Curve Fit \#1 to LWC_Bulk_M was plotted. A definite trend was noted for Wa $<120 \mathrm{lbm} / \mathrm{s}$, shown in Fig 16b. Therefore, an adjustment to the curve was developed to capture this Wa effect. It is labeled 'Curve Fit, Wa Adj.' in Fig 16a.

\section{Particle Size}

A more complete description of the particle size acquisition, data processing, and final PSD results can be found in a companion paper, Ref. [23]. Reported here are only the initial PSD results provided in a timely fashion to begin creating calibration curves for the Median Volumetric Diameter, MVD in support of the engine test. MVD can also be denoted by Dv50 or Dv0.5, where v indicates volume followed by the percent or decimal. It is important to understand that the curve fit results presented here were based upon the bestavailable data at the time. Since then, refinements to the data processing may have changed some of the final values.

Only the PSD measurements made at duct center were used to develop the MVD curve fits. The HSI-FPDR data were used for IC clouds, while the PDI data were used for SCL clouds. PSD data from two SCL sprays (Escort 269 and 277) are shown in Table 3; the corresponding cumulative volume plots are shown in Fig. 17. Particle diameters at different cumulative volume levels were given. With Escort 269, PSL produced smaller drops. Note that the Dv0.5 from the HSI-FPDR is twice that of the PDI. This is because the HSI cannot resolve the lower end of the particle spectrum, and therefore biases the distribution toward higher values. When the drops are much larger, as shown with Escort 277, the two instruments have much better agreement as the contribution of small drops is greatly reduced.

Also provided were several levels of processing: raw, pvc and fit. Raw values correspond to the real-time results, pvc corresponds to probe-volume corrected results, and fit refers to a Generalized Extreme Value (GEV) probability function (PDF) being applied to the count distribution to account for low counting 
statistics at the higher end of the size spectrum, Ref. [23]. After consultation with the wider team, it was decided that while the fit version was promising, there was not enough data to defend its use at the time the curves had to be generated. Thus, the pvc values were used for this MVD curve fit analysis.

Table 3. Sample of preliminary particle size data delivered after the initial round of processing.

\begin{tabular}{|c|c|c|c|c|c|c|c|}
\hline Escort & unit & analysis & $\mathrm{d}_{\mathrm{v} 0.10}$ & $\mathrm{~d}_{\mathrm{v} 0.25}$ & $\mathrm{~d}_{\mathrm{v} 0.50}$ & $\mathrm{~d}_{\mathrm{v} 0.90}$ & $\mathrm{~d}_{\mathrm{v} 0.99}$ \\
\hline & & & (um) & (um) & (um) & (um) & (um) \\
\hline \multirow[t]{6}{*}{269} & \multirow[t]{3}{*}{ HSI-FPDR } & raw & 15.1 & 17.6 & 21.0 & 28.9 & 36.5 \\
\hline & & pvc & 15.0 & 17.4 & 20.9 & 28.8 & 36.4 \\
\hline & & fit & 14.8 & 17.3 & 20.9 & 29.1 & 37.0 \\
\hline & \multirow[t]{3}{*}{ PDI } & raw & 7.6 & 9.7 & 12.7 & 20.8 & 29.0 \\
\hline & & pvc & 6.8 & 9.0 & 11.9 & 19.9 & 27.7 \\
\hline & & fit & 6.9 & 9.0 & 11.8 & 19.4 & 27.6 \\
\hline \multirow[t]{6}{*}{277} & \multirow[t]{3}{*}{ HSI-FPDR } & raw & 29.0 & 39.9 & 58.8 & 120.7 & 147.6 \\
\hline & & pvc & 28.8 & 39.6 & 58.2 & 120.4 & 147.5 \\
\hline & & fit & 28.5 & 38.4 & 55.1 & 107.5 & 145.7 \\
\hline & \multirow[t]{3}{*}{ PDI } & raw & 27.3 & 40.6 & 60.6 & 115.4 & 143.8 \\
\hline & & pvc & 23.4 & 35.9 & 55.6 & 111.8 & 143.6 \\
\hline & & fit & 22.2 & 33.9 & 55.2 & 110.7 & 141.1 \\
\hline
\end{tabular}

TableCurve3D ${ }^{\circledR}$ was used to fit each of the MVD data sets. All of the MVD data are shown in Fig. 18. Fig. 18a shows the Mod1 IC results, while the Standard IC results are shown in Fig. 18b. Figure 18c shows the Mod1 SCL results. The plots present MVD vs DeltaP along Pair lines spanning all flight conditions. It was not clear whether the scatter in the data was within measurement accuracy or due to the range of flight conditions. Further investigation will be conducted with the final data set. For reasons described earlier, regions of valid curve fit data are quite limited. For Mod1 IC, the curves are valid for $15 \leq$ Pair $\leq 35$ psig and $9 \leq$ DeltaP $\leq 110$ psid; Std IC curves from $25 \leq$ Pair $\leq 45$ psig and $35 \leq$ DeltaP $\leq 70$ psid. The Mod 1 SCL are valid from $4 \leq$ Pair $\leq 22$ psig and $4 \leq$ DeltaP $\leq 62$ psid. With this, the confidence level in these results is about $\pm 25 \%$. The goodness of fit for all IC and SCL cases are shown in Fig. 19 .

\section{Conclusions}

This paper is one of three that discuss the 2017 characterization effort of NASA Glenn's Propulsion Systems Lab. Described herein are the instrumentation, sample results, Cloud Uniformity, TWC and MVD cloud characterization curves for both ice crystal and supercooled liquid clouds. Further detail of the particle size distribution acquisition and final results of the can be found in Ref. [23], while a description of the air temperature and humidity, both cloud off and cloud on, can be found in Ref. [22].

This characterization effort began with new cloud uniformity objectives - to push the cloud as much as possible to the edges of the duct. With the light extinction tomography system, five nozzle patterns were identified that were fairly uniform, within $\pm 20 \%$, to about 3-in from the duct wall. At the same time, the facility parameters necessary to produce exactly supercooled liquid were identified and fixed. Significant evaporation for the target atmospheric flight conditions was forecasted and observed. For example, $4 \mathrm{~g} / \mathrm{m} 3$ issued from the nozzles, but only $1 \mathrm{~g} / \mathrm{m} 3$ was measured at the DEP. 
TWC measurements were made at duct center with an IKP2 in ice crystal conditions and a Multi-wire in supercooled liquid conditions. These centerline measurements were combined with the Concentration Factor from tomography to obtain a bulk TWC. Curves were developed to best fit the data.

The PSD measurements made at duct center were used to develop the MVD curve fits. The preliminary HSI-FPDR data were used for ice crystal clouds, and the PDI were used for supercooled liquid cloud. Since then, and with considerable effort, final values have been produced. These are reported in Ref. [23].

In summary, nine days were allocated to optimize and fix nozzle patterns, identify conditions required to produce exactly supercooled liquid, characterize three cloud parameters, CF, TWC, MVD, in new-to-PSL atmospheric flight conditions that spanned three Appendices: D/P, C and O. Lack of test time lead to a lack of repeats, and data was acquired at centerline only. Even with those challenges, reasonably well-ordered TWC and MVD curve fits were developed.

A future effort will include repeating select cases, and capturing radial profiles of TWC and PSD in both ice crystal and supercooled liquid conditions.

\section{Acknowledgments}

Thanks to the sponsor, NASA's Aeroscience and Evaluation Test Capability, AETC, project under the Advanced Air Vehicles Program. 


\section{FIGURES}

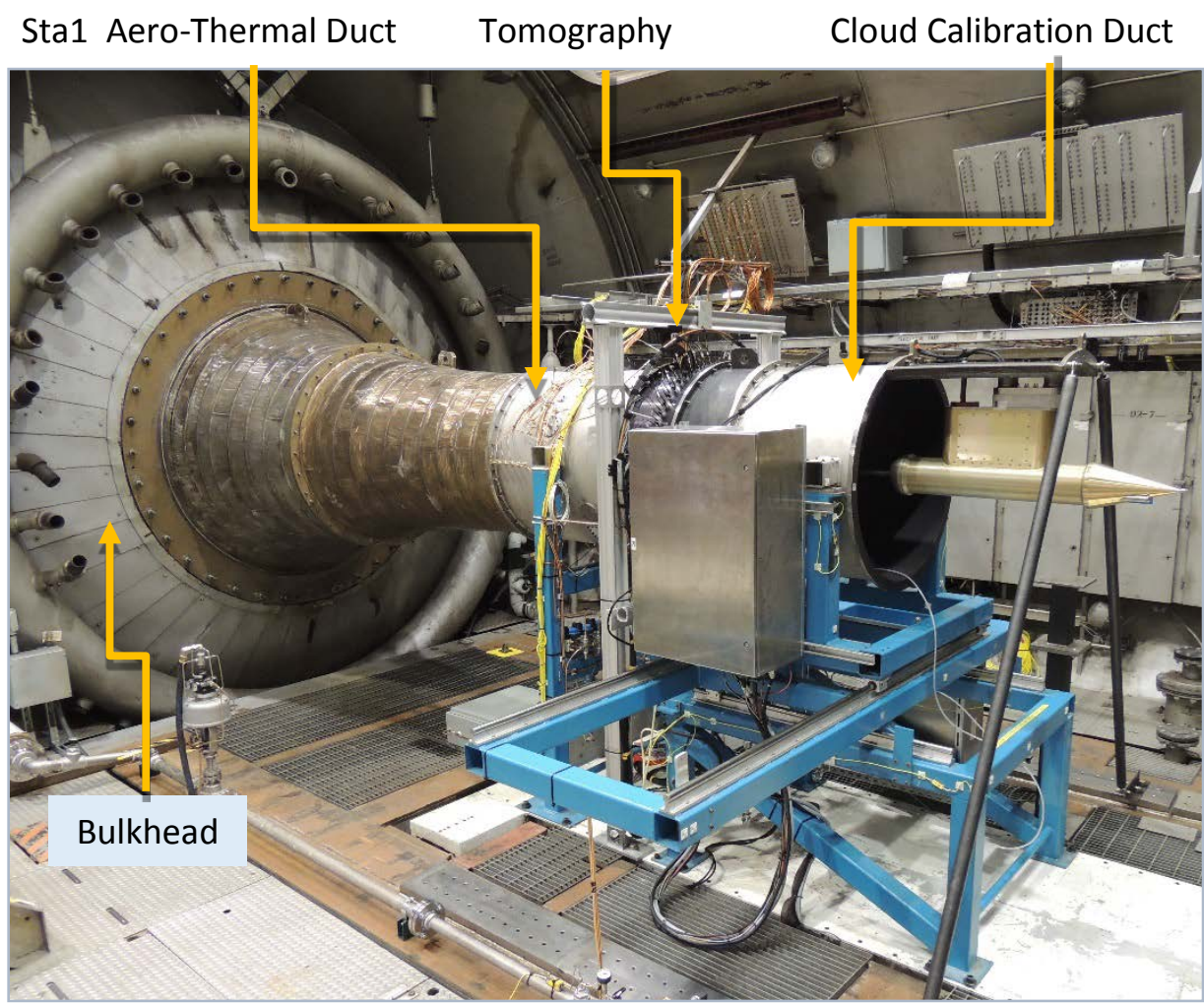

Figure 1. PSL base calibration configuration. The bulkhead and constant area ducts are indicated: AeroThermal duct measuring pressure, temperature and specific water vapor; Tomography and Raman Duct; Cloud calibration duct measuring water content and particle size. The Station 1 plane is at the axial center of the aero-thermal duct.
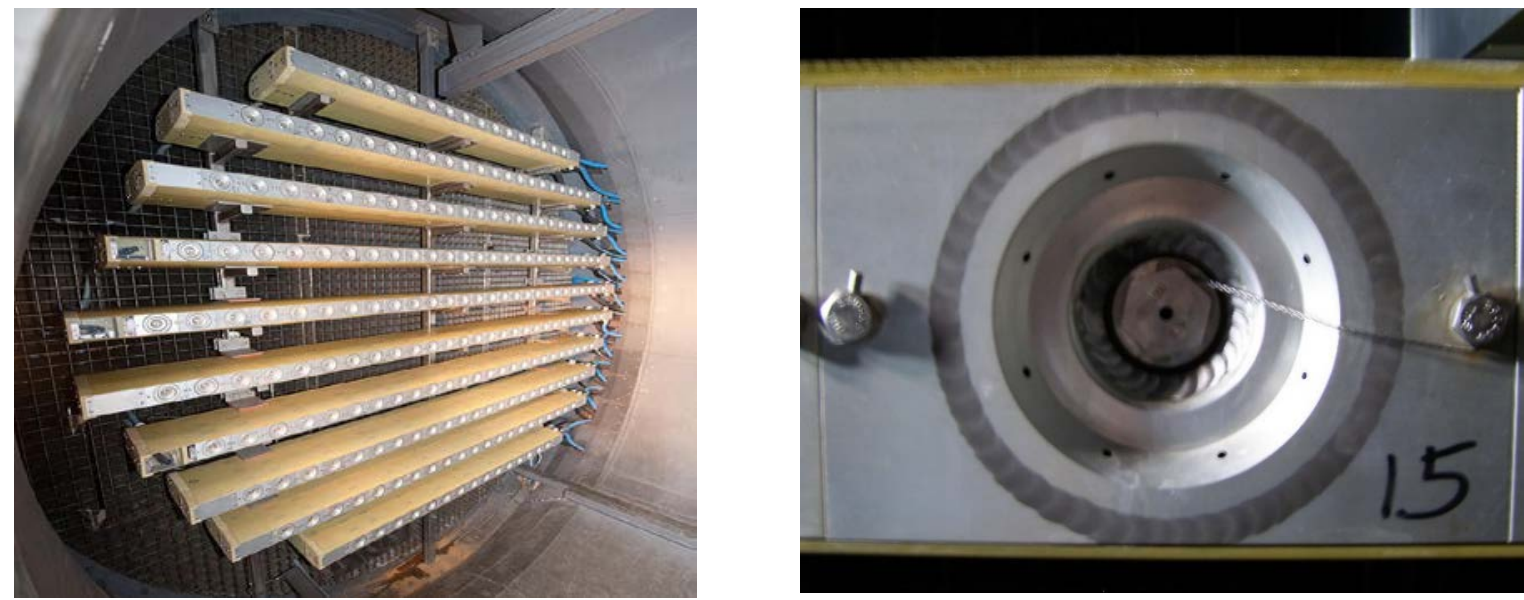

Figure 2. Spraybar setup in PSL Plenum: (a) overview, (b) close-up of nozzle exit and cooling air ports. 


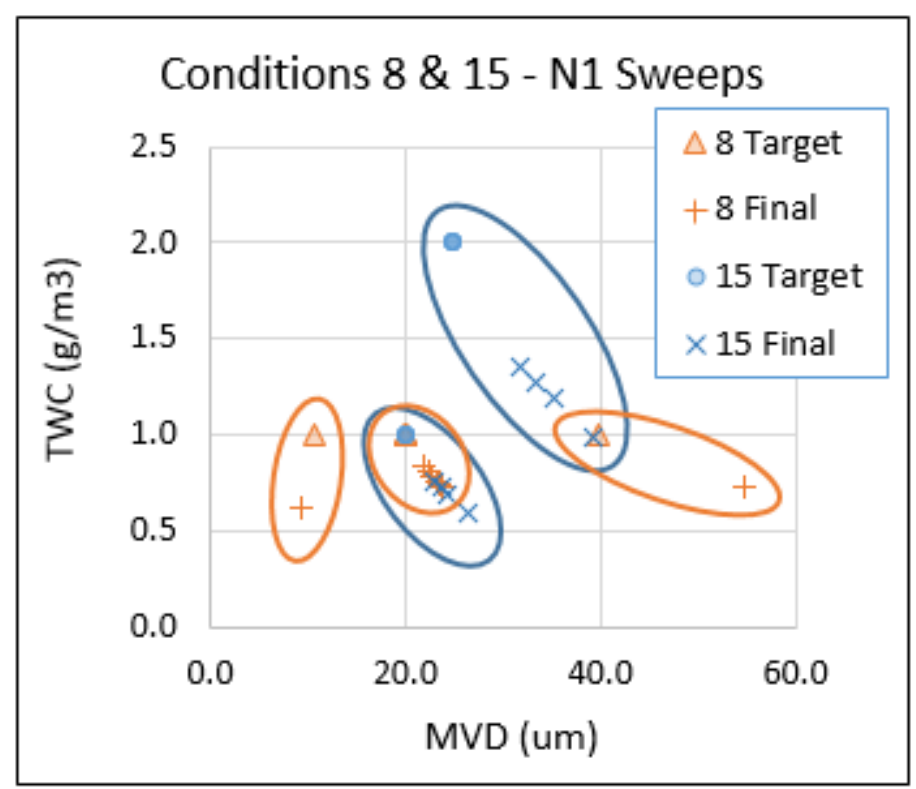

Figure 3. Predicted effects of a fan speed, N1, sweep on SCL cloud evaporation. From five target conditions in the plenum, a family of changes appear at the DEP (Final), indicated with the data labels.

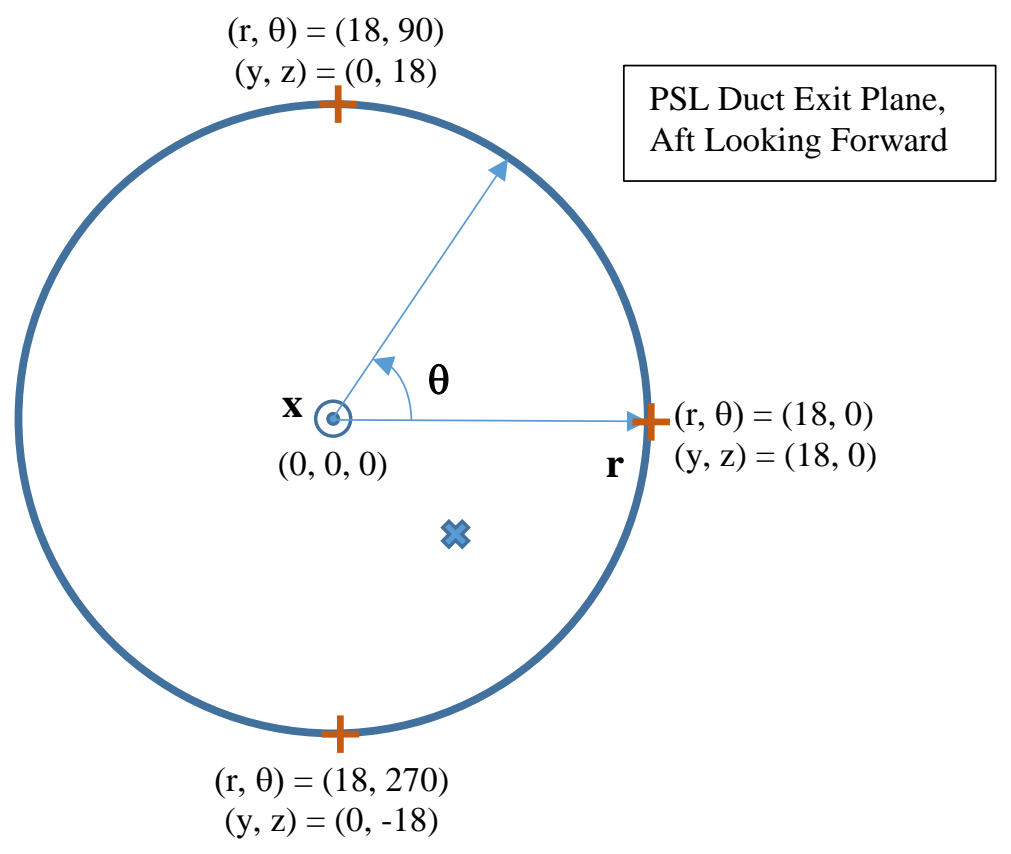

Figure 4. PSL Cloud Instrumentation Coordinate System, Aft Looking Forward (ALF). Coordinate origin is the center of the DEP. For both Cylindrical coordinates $(\mathrm{x}, \mathrm{r}, \theta)$ and Cartesian $(\mathrm{x}, \mathrm{y}, \mathrm{z})$ the axial direction, $x$, is positive downstream. The blue $X$ is at $(0,9,315)$ or $(0,9,-9)$. 

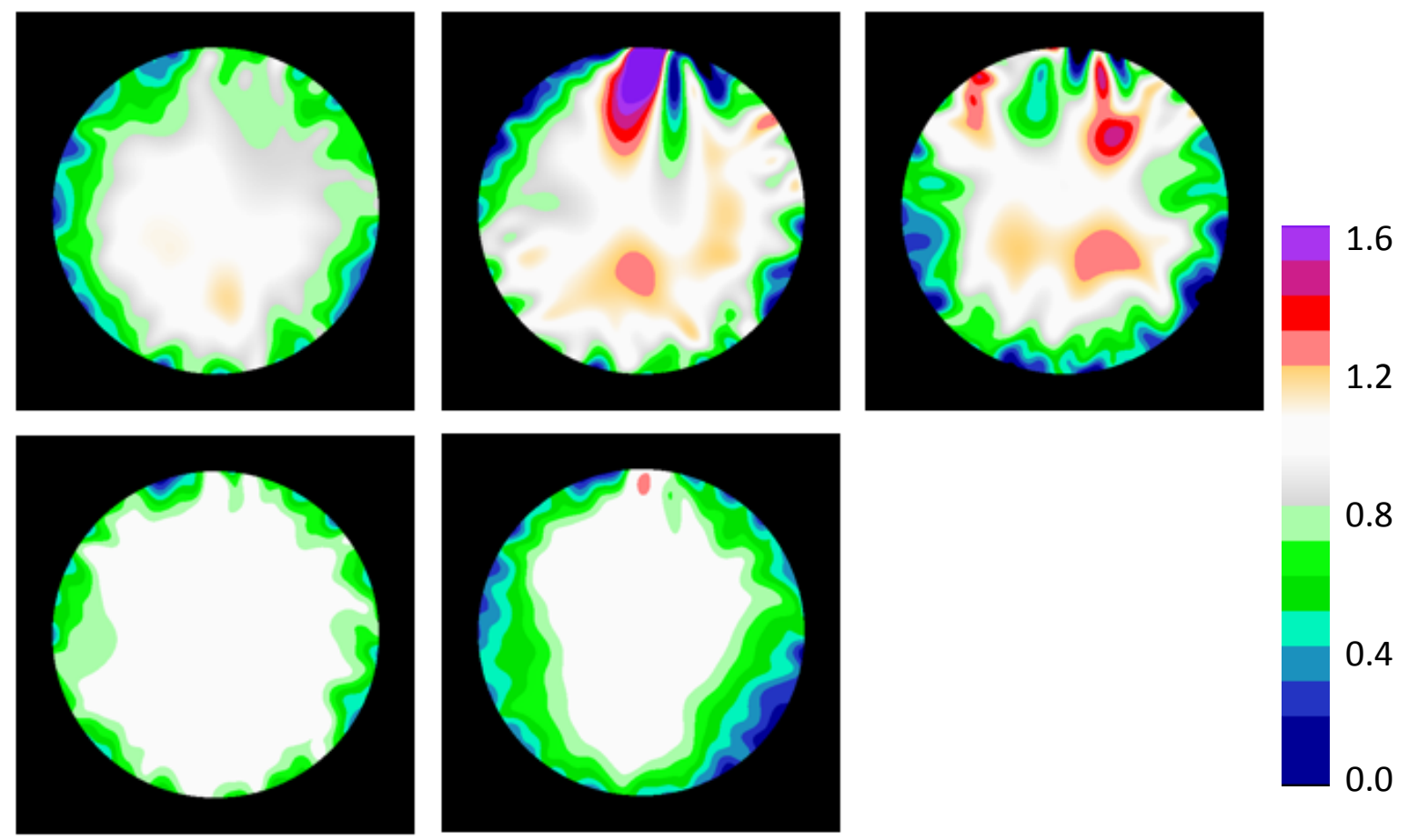

Figure 5. a-c: Mod1 Uniformity with Nozzle Patterns a) 84, b) 36, c) 26, and d-e: Std Uniformity with Nozzle Patterns d) 77 at (80, 40; 40, e) 43 at (90, 40; 50).

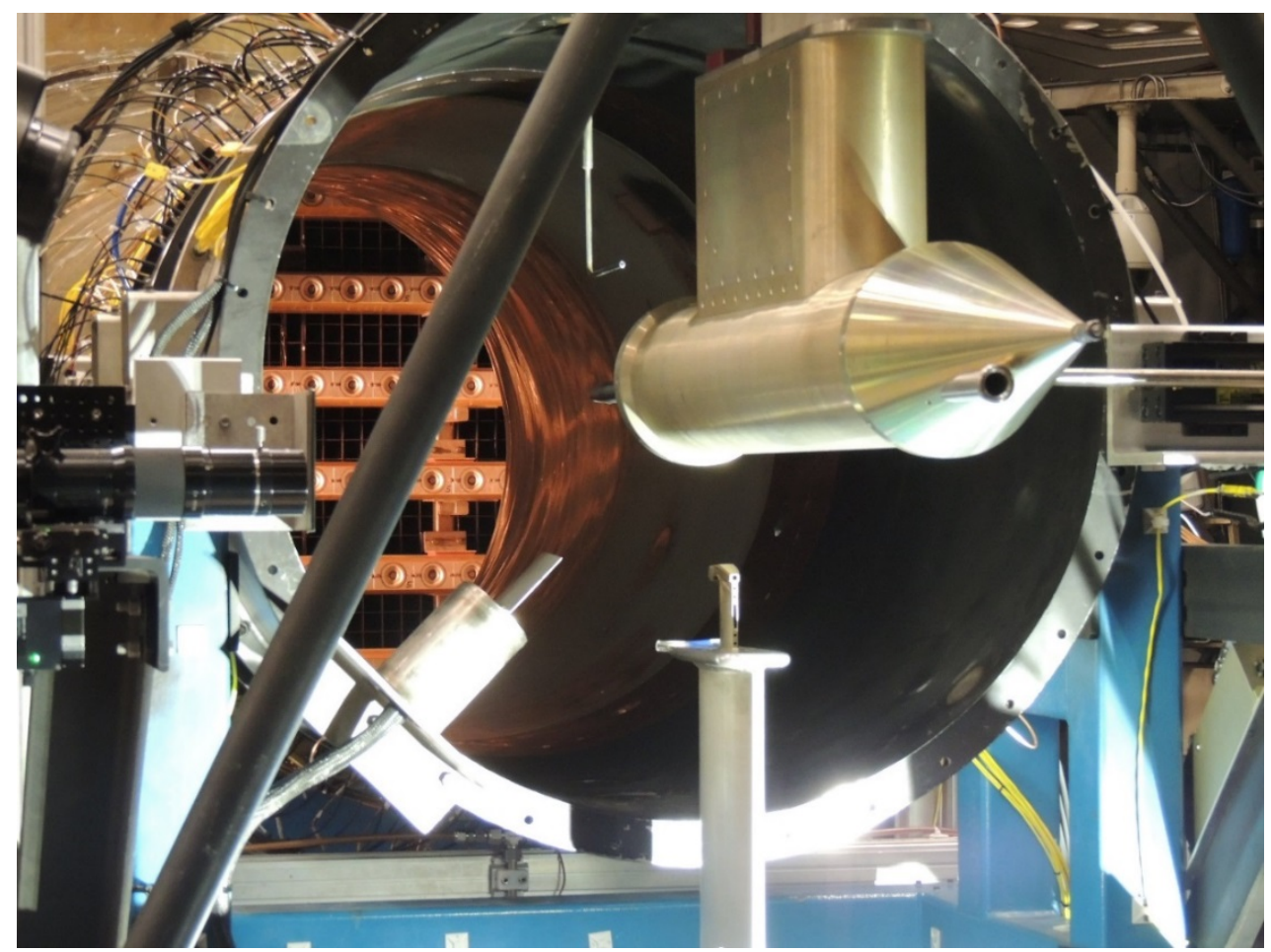

Figure 6. IKP2 installed at duct center. Also pictured are the bent tube humidity measurement, LiBack1, at $90^{\circ}$, ICD at $225^{\circ}$, TAT at $270^{\circ}$, and RFP at $0^{\circ}$. 


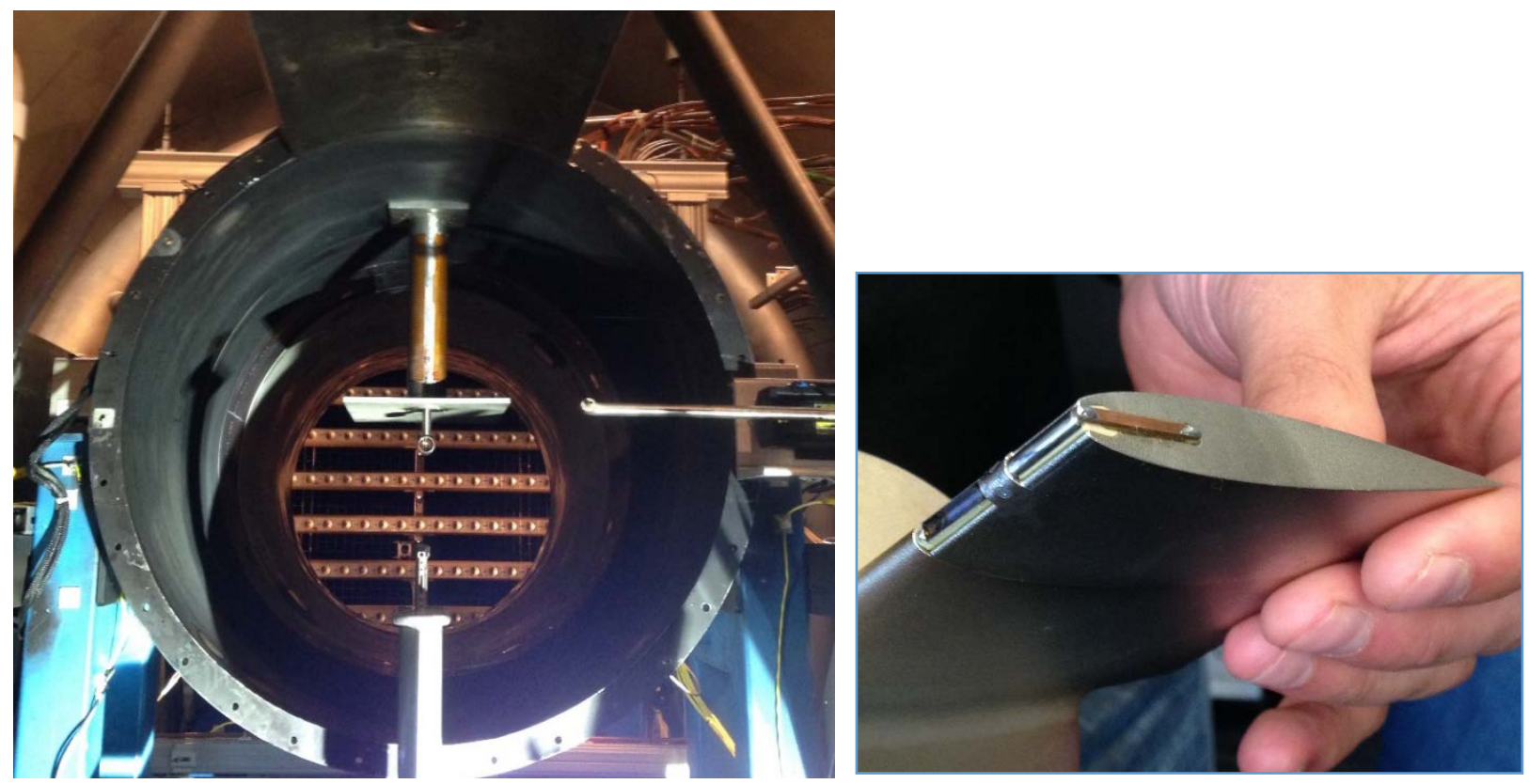

Figure 7. Multi-wire installed in Duct, (b) Ice Crystal Detecor close-up.

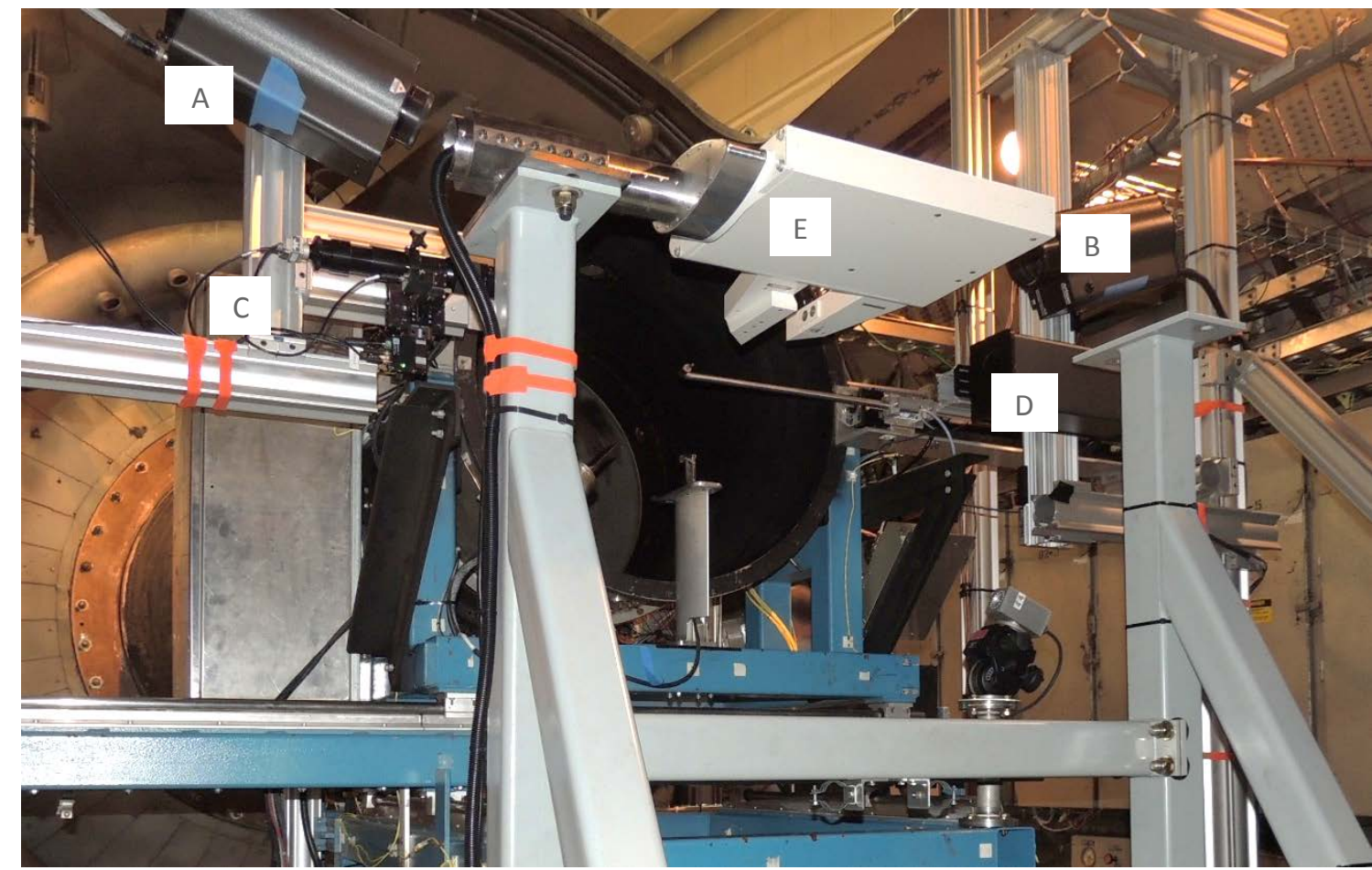

Figure 8. Artium particle sizing instrumentation, modular Phase Doppler Interferometer, PDI, modular High Speed Imaging probe (HSI) and HSI-Flight Probe, Dual Range, HSI-FPDR, as installed in PSL. A: PDI Transmitter, B: PDI Receiver, C: HSI Receiver, D: HSI Transmitter, E: HSI-FPDR 

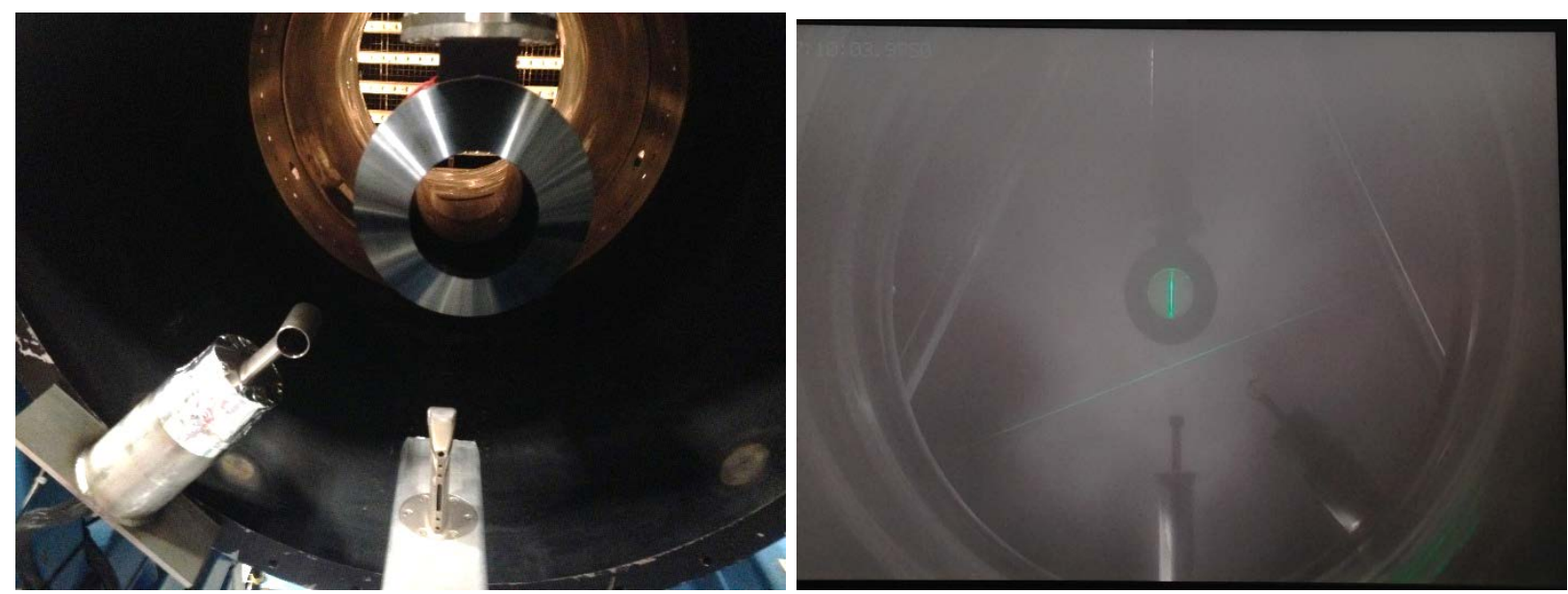

Figure 9. Raman probe head installed at duct center. Also seen are the multi-wire and TAT probe: a) aft looking forward, b) forward looking aft from spraybar camera, in cloud. PDI laser also visible

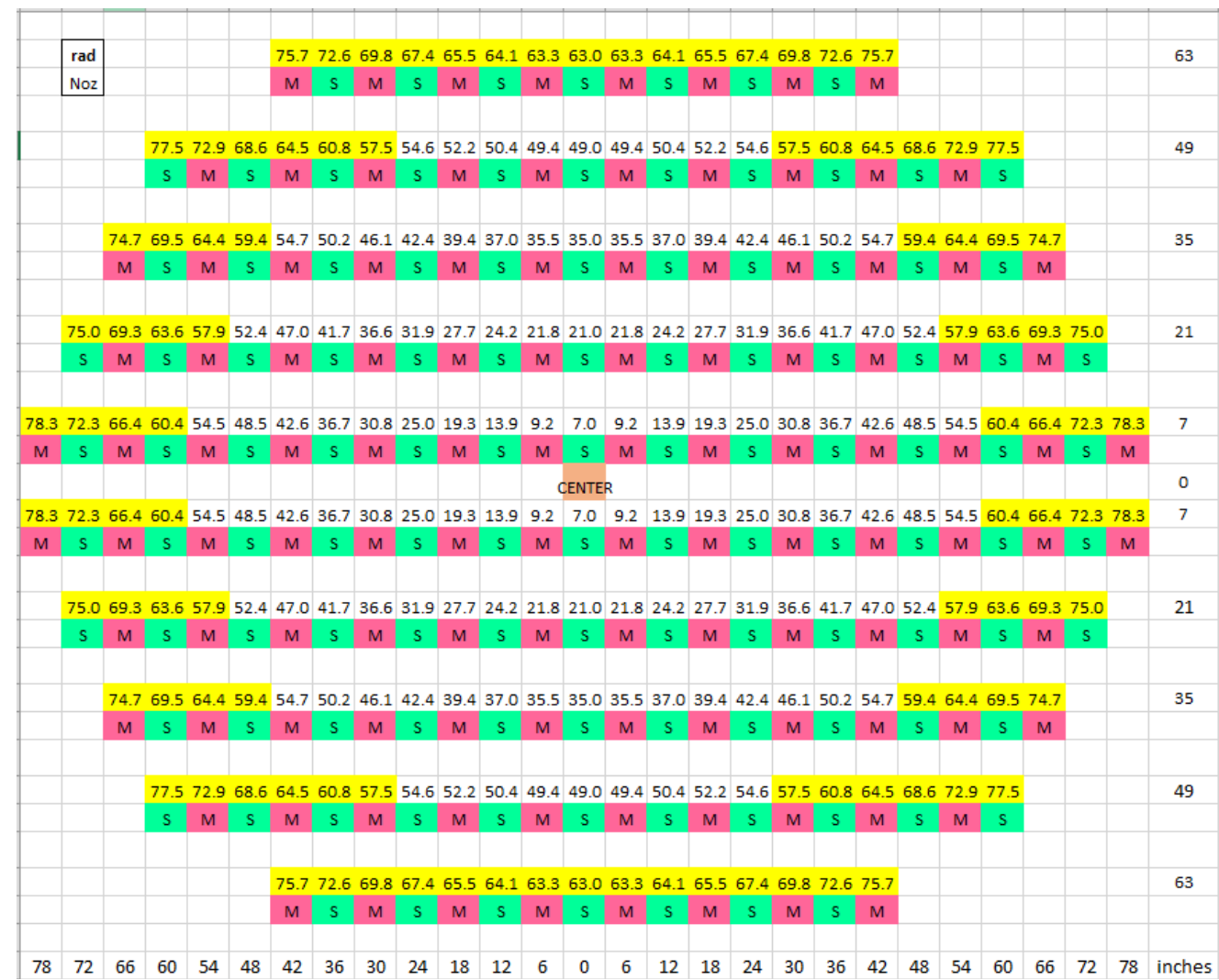

Figure 10. PSL Nozzle Pattern Map. Shown are the locations of the Mod1 (magenta) and Standard (green) nozzles, with their radial distance from center. Yellow highlights show change in nozzles allowed on; distance from 55 to 79 -in. 


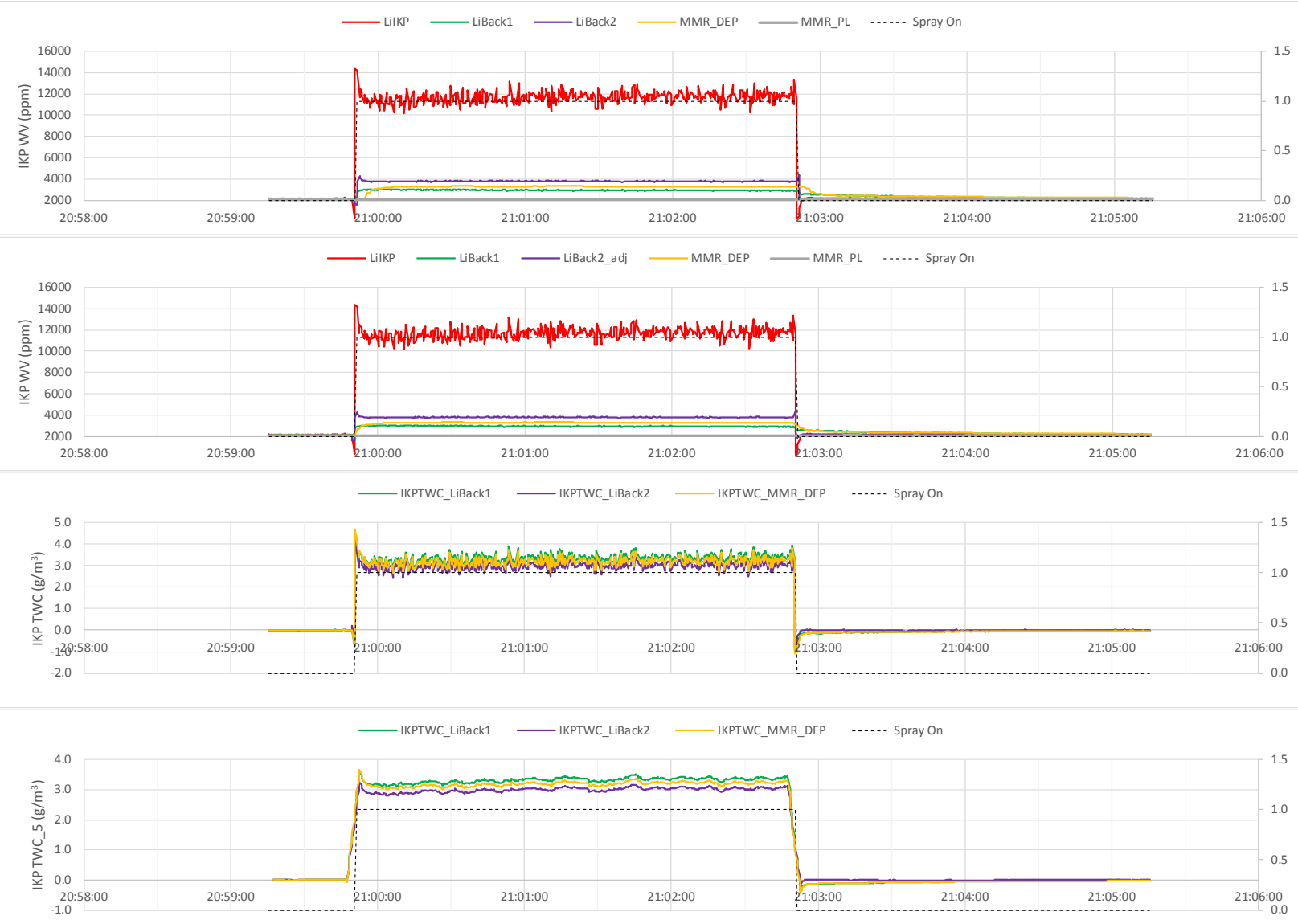

Figure 11. Sample IKP measurement time trace: a) direct measurements from IKP and background humidity probes, b) same as a), but time-synced, c) calculated 1-sec TWCs, d) 5-sec moving average TWCs.
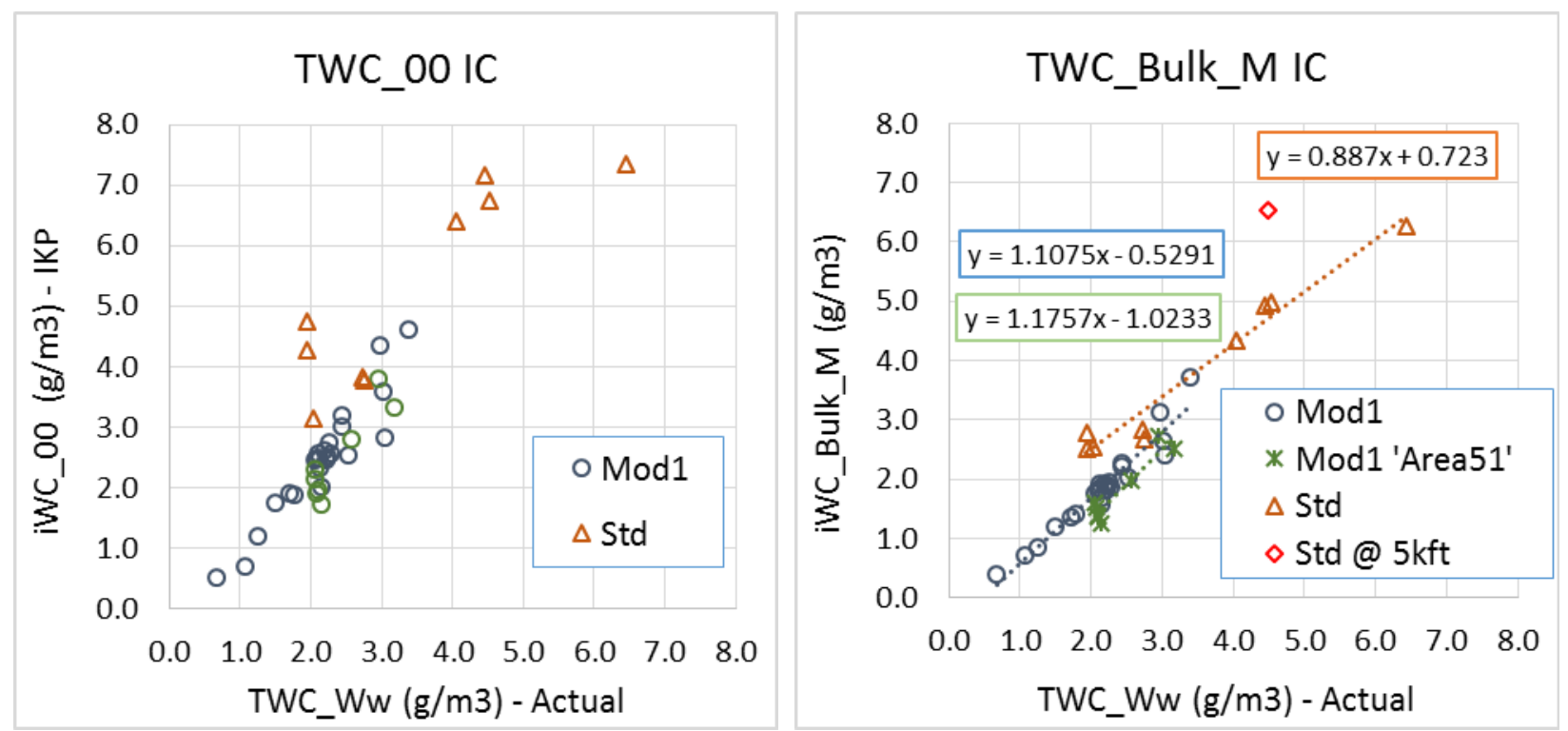

Figure 12. TWC in Ice Crystals with IKP2 for all atmospheric flight conditions. Basis TWC_Ww is calculated from actual (vs target) conditions. a) Measured IKP values at centerline, b) Bulk TWC from IKP and Tomography CF. Linear trendlines are color-coded and indicated. 

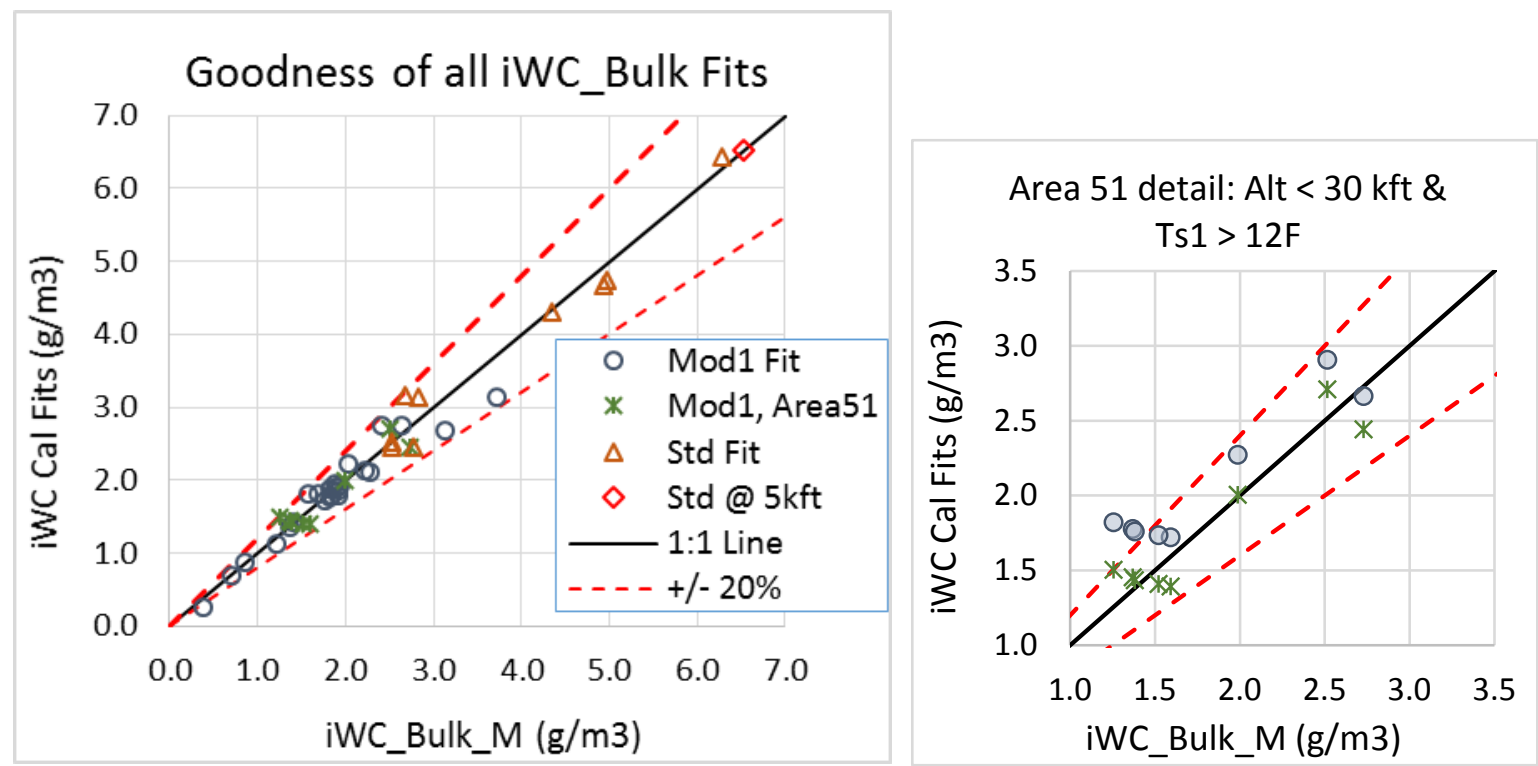

Figure 13. Goodness of TWC in IC conditions fit for all data. Inset: close up of Area 51, with the generic Mod1 curve fit, with its own curve fit.
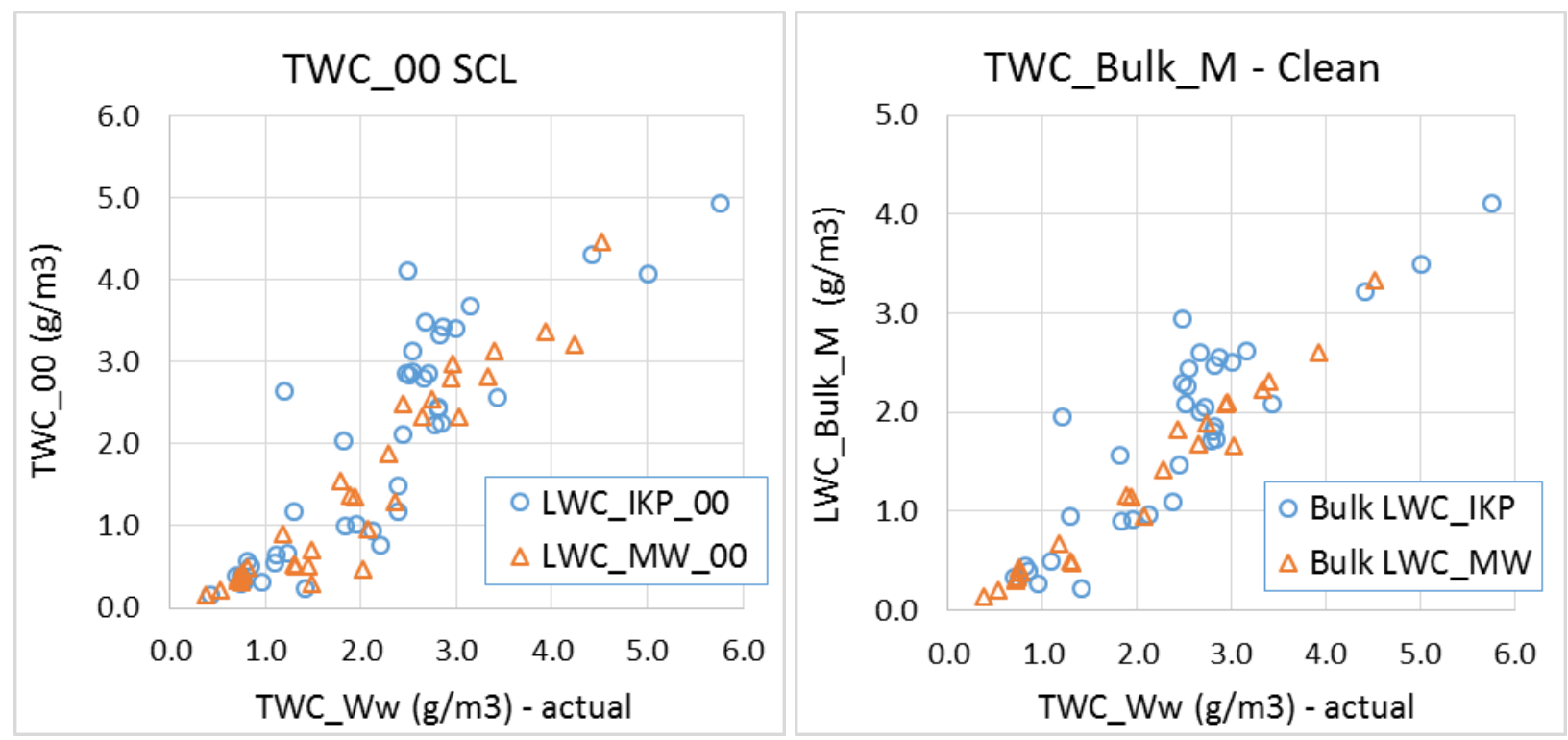

Figure 14. TWC in Supercooled Liquid with IKP2 and MW for all atmospheric flight conditions. Basis TWC_Ww is calculated from actual (vs target) conditions. a) Measured IKP and MW values at centerline, b) Bulk TWC from Tomography CF; data with contaminated tomography signal are not plotted. 


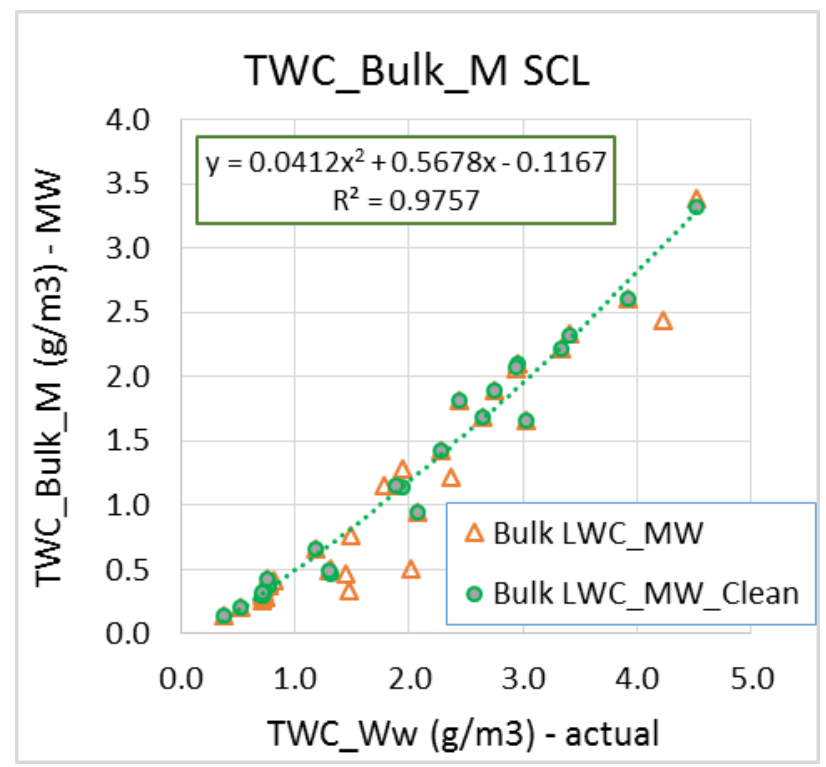

Figure 15. Developing a best fit LWC curve.
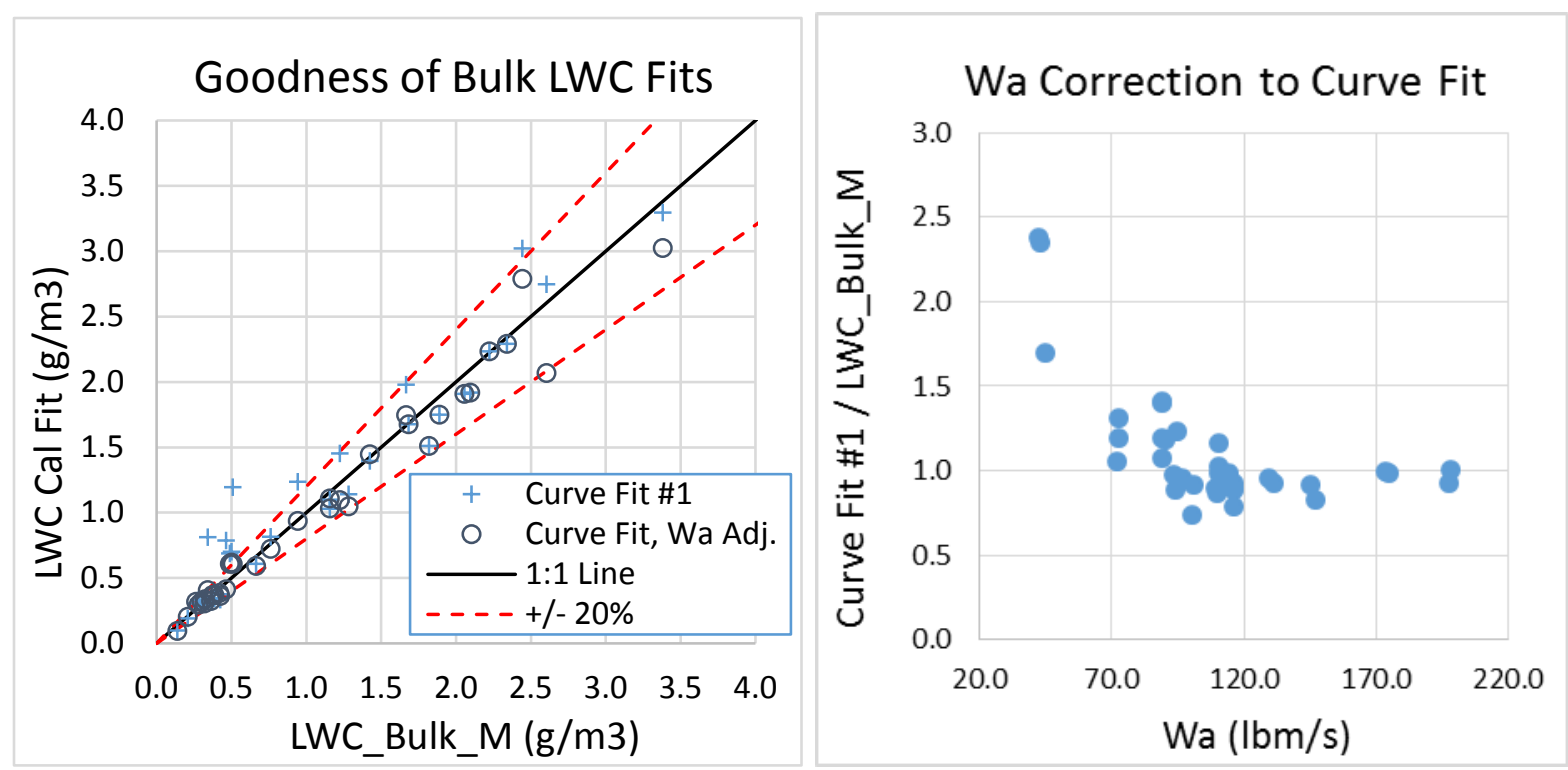

Figure 16. Goodness of TWC in SCL fits. a) all SCL data, b) plot showing the need for a Wa adjustment below $\mathrm{Wa}=120 \mathrm{lbm} / \mathrm{s}$ values. 

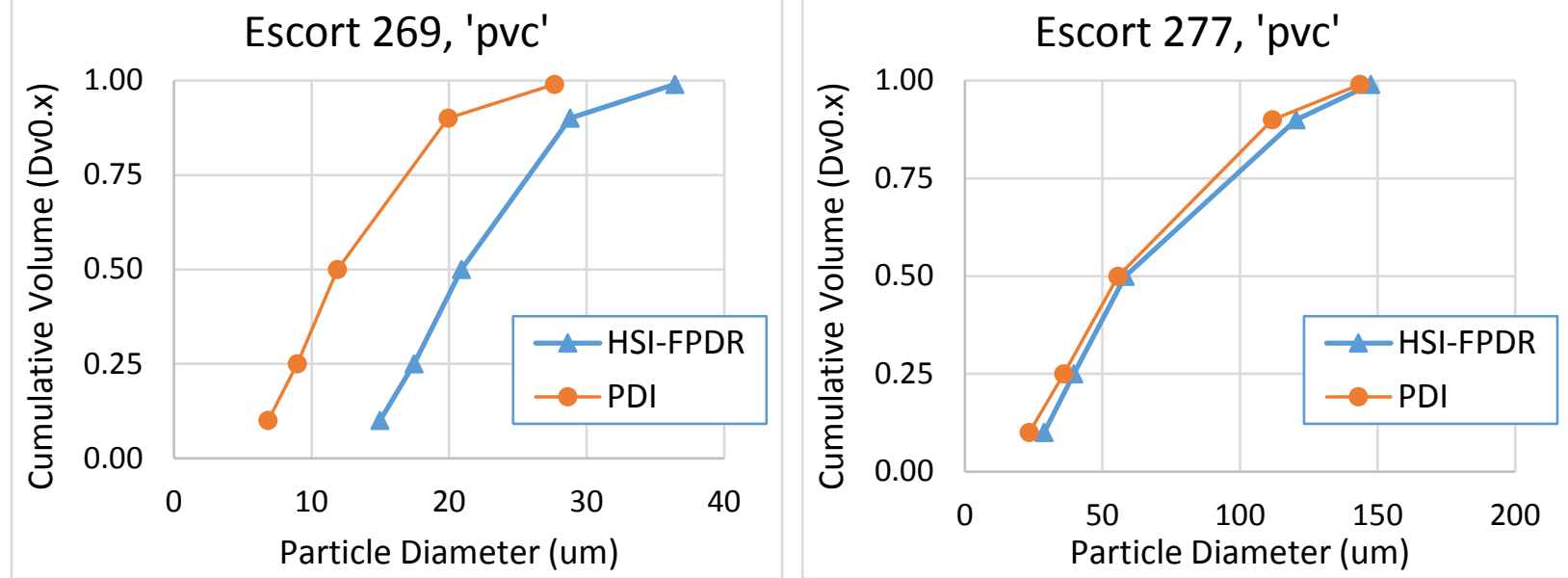

Figure 17. Sample cumulative volume output of initial PSD analysis from the HSI-FPDR and PDI in SCL conditions for a) Escort 269 small drop and b) Escort 277 large drop conditions.
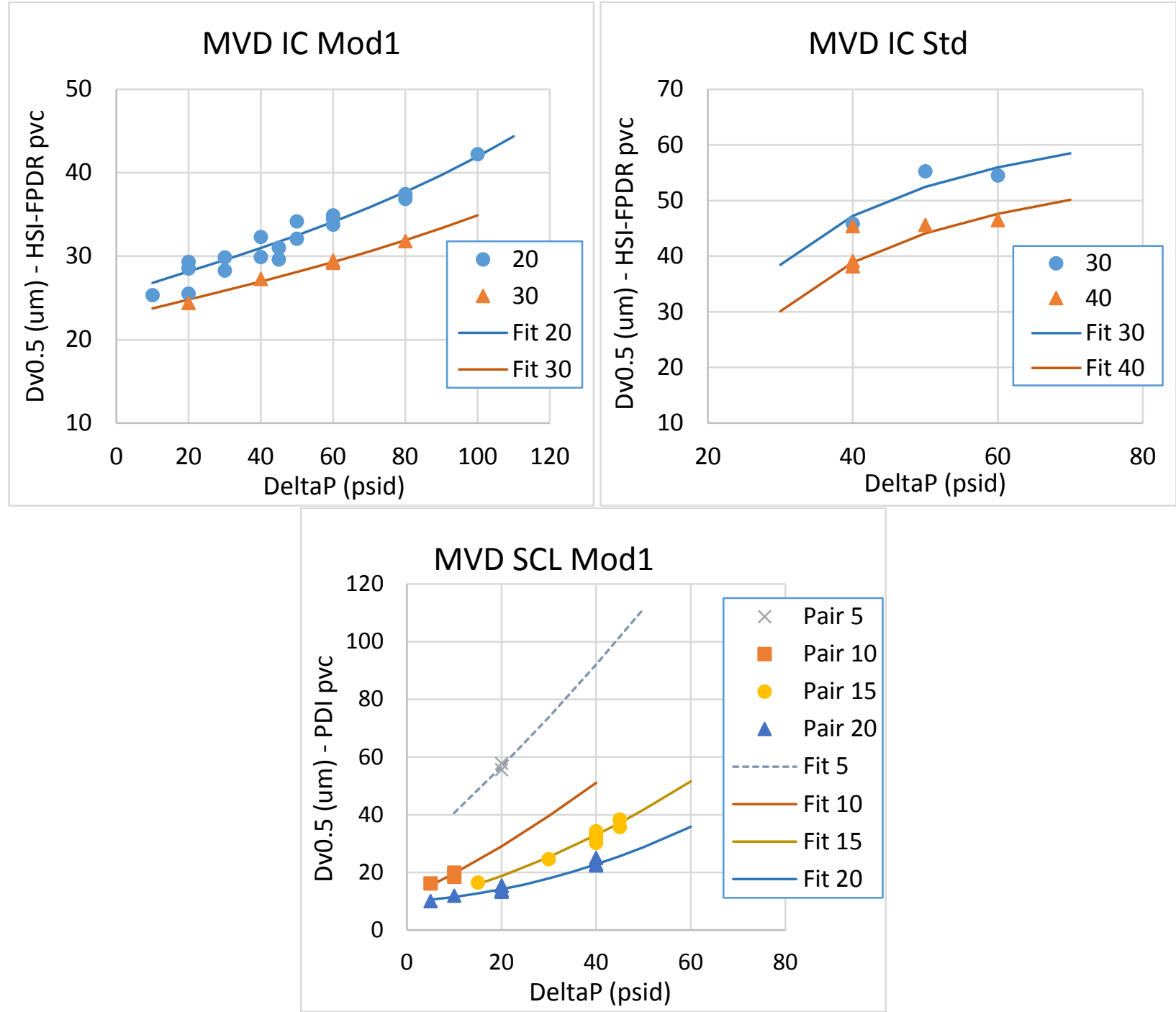

Figure 18. MVD data with curve fits: a) IC with Mod1, b) IC with Std, c) SCL with Mod1. 

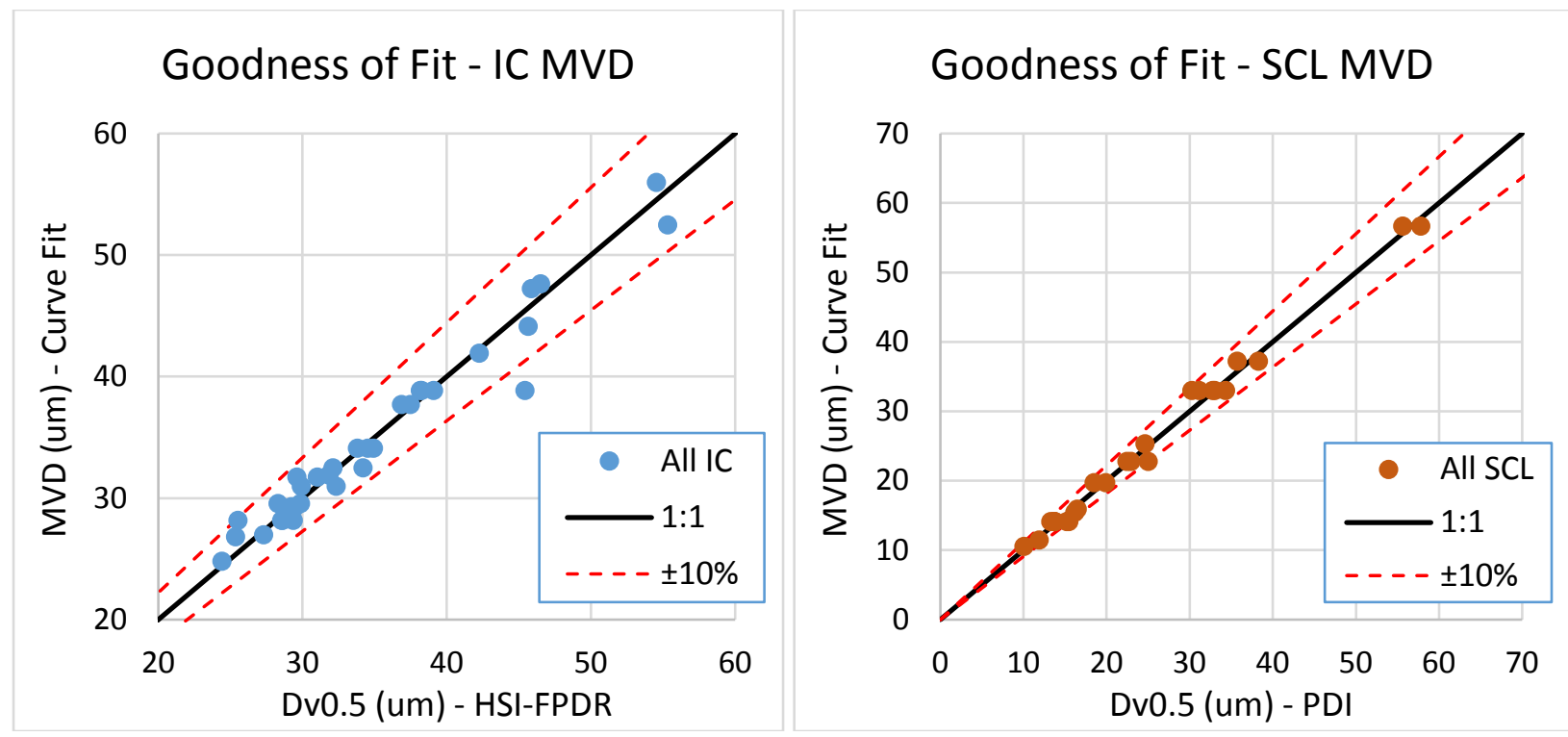

Figure 19. Goodness of MVD curve fits a) all IC conditions, b) all SCL conditions. 


\section{References}

1. Griffin, T.A., Lizanich, P., and Dicki, D.J., "PSL Icing Facility Upgrade Overview," 6th AIAA Atmospheric and Space Environments Conference, Atlanta, GA, June 16-20, 2014, AIAA 2014-2896.

2. Oliver, M. J. "Validation Ice Crystal Icing Engine Test in the Propulsion Systems Laboratory at NASA Glenn Research Center," 6th AIAA Atmospheric and Space Environments Conference, Atlanta, GA, June 16-20, 2014, AIAA2014-2898.

3. Goodwin, R.V., Dischinger, D.G., "Turbofan Ice Crystal Rollback Investigation and Preparations Leading to Inaugural Ice Crystal Engine Test at NASA PSL-3 Facility," 6th AIAA Atmospheric and Space Environments Conference, Atlanta, GA, June 16-20, 2014, AIAA-2014-2895.

4. Flegel, A.B., Oliver, M.J., "Preliminary Results from a Heavily Instrumented Engine Ice Crystal Icing Test in a Ground Based Altitude Test Facility," 8th AIAA Atmospheric and Space Environments Conference, Washington, D.C, June 13-17, 2016, AIAA 2016-3894. DOI: 10.2514/6.2016-3894.

5. Goodwin, R.V., Fuleki, D., "Engine Preparation and Instrumentation for the Second Ice Crystal Engine Test at NASA PSL-3 test Facility," 8th AIAA Atmospheric and Space Environments Conference, Washington, D.C, June 13-17, 2016, AIAA 2016-3892, DOI: 10.2514/6.2016-3892.

6. Van Zante, J.F., Bencic, T.J., and Ratvasky, T.P., "Update on the NASA Glenn Propulsion Systems Lab Ice Crystal Cloud Characterization (2015)", 2016 AIAA Aviation. 8th AIAA Atmospheric and Space Environments Conference, Washington, D.C, June 13-17, 2016, AIAA 2016-3897.

7. Van Zante, J. F., and Rosine, B. M. "NASA Glenn Propulsion Systems Lab: 2012 Inaugural Ice Crystal Cloud Calibration," 6th AIAA Atmospheric and Space Environments Conference, Atlanta, GA, June 16-20, 2014, AIAA 2014-2897.

8. Veres, J.P., Jorgenson, P.C.E., Jones, S.M., Nili, S., “Modeling of a Turbofan Engine with Ice Crystal Ingestion in the NASA Propulsion Systems Laboratory,” ASME IGTI 2017 Turbo Expo, Charlotte, NC, June 26-30, 2017, GT2017-63202.

9. A. M. Kinney, Inc., Cox \& Company, PEDCO, A-P-T Research, "PSL Icing Project - Icing System Final Design Report - 90\% submittal”, 2.0 Icing System Analysis, Feb 26, 2010.

10. Struk, Peter M., Tsao, Jen-Ching, and Bartkus, Tadas, P., "Plans and Preliminary Results of Fundamental Studies of Ice Crystal Icing Physics in the NASA Propulsion Systems Laboratory," $8^{\text {th }}$ AIAA Atmospheric and Space Environments Conference, 13-17 June, 2016, Washington D.C., AIAA-3738.

11. Oliver, M.J. and Struk, P. "An Aerothermal Analysis for the Propulsion Systems Laboratory at NASA Glenn Research Center," 10th AIAA Atmospheric and Space Environments Conference, Atlanta, GA, June 16-20, 2018, Invited Presentation, Update on Recent Ice Crystal Icing Facilities and Research Session.

12. Bartkus, T. P., Struk, P. M., Tsao, J. C., and Van Zante, J. F., "Numerical Analysis of Mixed-Phase Icing Cloud Simulations in the NASA Propulsion Systems Laboratory," 8th AIAA Atmospheric and Space Environments Conference, AIAA, Washington D.C., 2016. doi: 10.2514/6.2016-3739.

13. Bartkus, T. P., Struk, P. M., and Tsao, J.-C., "Comparisons of Mixed-Phase Icing Cloud Simulations with Experiments Conducted at the NASA Propulsion Systems Laboratory," 9th AIAA Atmospheric and Space Environments Conference. AIAA, Denver, CO, 2017. doi: 10.2514/6.2017-4243

14. Bartkus, T. P., Struk, P. M., and Tsao, J. C., "Development of a Coupled Air and Particle Thermal Model for Engine Icing Test Facilities," SAE Int. J. Aerosp. Vol. 8, No. 1, 2015. pp. 15-32. doi: 10.4271/2015-01-2155. 
15. Bencic, T.J., Fagan, A.F., Van Zante, J.F., Kirkegaard, J.P., Rohler, D.P., Maniyedath, A., and Izen, S.H., "Advanced Optical Diagnostics for Ice Crystal Cloud Measurements in the NASA Glenn Propulsion Systems Laboratory,” 5th AIAA Atmospheric and Space Environments Conference, AIAA 2013-2678, June 2013.

16. Davison, C., Strapp, J.W., Lilie, L.E., Ratvasky, T.P, and Dumont, C., "Isokinetic TWC Evaporator Probe: Calculations and Systemic Error Analysis," 8th AIAA Atmospheric and Space Environments Conference, 13 - 17 June 2016, Washington, D.C., AIAA 2016-4060. DOI: 10.2514/6.2016-4060

17. Strapp, J.W., Lilie, L.E., Ratvasky, T.P., Davison, C., Dumont, C., "Isokinetic TWC Evaporator Probe: Development of the IKP2 and Performance Testing for the HAIC-HIWC Darwin 2104 and Cayenne 2015 Field Campaigns," $8^{\text {th }}$ AIAA Atmospheric and Space Environments Conference, 13-17 June, 2016, Washington D.C., AIAA 2016-4059, DOI: 10.2514/6.2016-4059.

18. Lilie, L., Emery, E., Strapp, J.W., Emery, J., “A Multiwire Hot-Wire Device for Measurement of Icing Severity, Total Water Content, Liquid Water Content, and Drop Diameter," $43^{\text {rd }}$ AIAA Aerospace Sciences Meeting and Exhibit, 10-13 January 2005, Reno, Nevada, AIAA-2005-859.

19. Steen Laura E., Ide, Robert F., and Van Zante, Judith F., “An Assessment of the Icing Blade and the SEA Multi-Element Sensor for Liquid Water Content Calibration of the NASA GRC Icing Research Tunnel,” 8th AIAA Atmospheric and Space Environments Conference, 13-17 June, 2016, Washington D.C., AIAA 2016-4051.

20. Rigby, D.L., Struk, P.M., and Bidwell, C., "Simulation of fluid flow and collection efficiency for an SEA multi-element probe," 6th AIAA Atmospheric and Space Environments Conference, AIAA 2014-2752, Atlanta, 2014. doi: $10.2514 / 6.2014-2752$.

21. Lilie, L.E., Sivo, C.P., Bouley, D.B., "Description and Results for a Simple Ice Crystal Detection System for Airborne Applications", 8th AIAA Atmospheric and Space Environments Conference, 13-17 June, 2016, Washington D.C., AIAA 2016-4058. DOI: 10.2514/6.2016-4058

22. Agui, J.H., Struk, P.M., and Bartkus, T.P “Total Temperature Measurements Using a Rearward Facing Probe in Supercool Liquid Droplet and Ice Crystal Clouds,” 10th AIAA Atmospheric and Space Environments Conference, AIAA Aviation Forum, 25-29 June 2018, Atlanta, GA (submitted for publication).

23. King, Michael C., Manin, J, Van Zante, J. F., Timko, E. N., Struk, P.M., "Particle Size Calibration Testing in the NASA Propulsion System Laboratory," $10^{\text {th }}$ AIAA Atmospheric and Space Environments Conference, 25-29 June, 2016, Atlanta, GA, AIAA (submitted for publication). 